\title{
Physical and remineralization processes govern the cobalt distribution in the deep western Atlantic Ocean
}

\author{
G. Dulaquais ${ }^{1}$, M. Boye ${ }^{1}$, M. J. A. Rijkenberg ${ }^{2,3}$, and X. Carton $^{4}$ \\ ${ }^{1}$ Laboratoire des Sciences de l'Environnement Marin UMR6539, Institut Universitaire Européen de la Mer UMS3113, \\ Technopôle Brest Iroise, Place Nicolas Copernic, 29280 Plouzané, France \\ ${ }^{2}$ Department of Marine Biology, University of Groningen, P.O. Box 14, 9750 AA Haren, the Netherlands \\ ${ }^{3}$ Department of Marine Chemistry and Geology, Royal Netherlands Institute for Sea Research, P.O. Box 59, \\ 1790 AB Den Burg, the Netherlands \\ ${ }^{4}$ Laboratoire de Physique des Océans, Université de Bretagne Occidentale - UFR Sciences, 6 avenue Le Gorgeu, C.S. 93837 , \\ 29238 Brest Cedex 3, France
}

Correspondence to: G. Dulaquais (gabriel.dulaquais@univ-brest.fr)

Received: 6 September 2013 - Published in Biogeosciences Discuss.: 16 October 2013

Revised: 23 January 2014 - Accepted: 28 January 2014 - Published: 24 March 2014

\begin{abstract}
The distributions of the bio-essential trace element dissolved cobalt (DCo) and the apparent particulate Co $(P C o)$ are presented along the GEOTRACES-A02 deep section from $64^{\circ} \mathrm{N}$ to $50^{\circ} \mathrm{S}$ in the western Atlantic Ocean (longest section of international GEOTRACES marine environment program). $P$ Co was determined as the difference between total cobalt ( $T$ Co, unfiltered samples) and $D C o$. $D C$ concentrations ranged from $14.7 \mathrm{pM}$ to $94.3 \mathrm{pM}$, and $P$ Co concentrations from undetectable values to $18.8 \mathrm{pM}$. The lowest $D C$ co concentrations were observed in the subtropical domains, and the highest in the low-oxygenated Atlantic Central Waters (ACW), which appears to be the major reservoir of $D C o$ in the western Atlantic. In the Antarctic Bottom Waters, the enrichment in $D C$ o with aging of the water mass can be related to suspension and redissolution of bottom sediments a well as diffusion of $D C$ fo from abyssal sediments. Mixing and dilution of deep water masses, rather than scavenging of $D C o$ onto settling particles, generated the meridional decrease of $D C$ along the southward large-scale circulation in the deep western Atlantic. Furthermore, the apparent scavenged profile of $D C$ o observed in the deep waters likely resulted from the persistence of relatively high concentrations in intermediate waters and low $D C$ co concentrations in underlaying bottom waters. We suggest that the 2010 Icelandic volcanic eruption could have been a source of $D C o$ that could have been transported into the core of the Northeast Atlantic Deep Waters. At intermediate depths, the high
\end{abstract}

concentrations of $D C$ recorded in the ACW linearly correlated with the apparent utilization of oxygen (AOU), indicating that remineralization of $D C$ could be significant (representing up to $37 \%$ of the DCo present). Furthermore, the preferential remineralization of phosphate $(\mathrm{P})$ compared to Co in these low-oxygenated waters suggests a decoupling between the deep cycles of $\mathrm{P}$ and Co. The vertical diffusion of $D C$ o from the ACW appears to be a significant source of $D C o$ into the surface waters of the equatorial domain. Summarizing, the dilution due to mixing processes rather than scavenging of $D C o$ and the above-mentioned remineralization could be the two major pathways controlling the cycling of $D C o$ into the intermediate and deep western Atlantic.

\section{Introduction}

In the context of the international GEOTRACES program, unprecedent efforts are underway to map the distribution of trace elements and isotopes in the global oceans. Cobalt (Co) is among the important micronutrients highlighted in this program. Dissolved cobalt ( $D C$ C) typically occurs at concentrations lower than $150 \mathrm{pM}$ in the open ocean (Knauer et al., 1982; Martin et al., 1990; Fitzwater et al., 2000; Saito and Moffett, 2001; Saito et al., 2004; Ellwood, 2008; Noble et al., 2008; Pohl et al., 2011; Bown et al., 2011), requiring sensitive analytical techniques for its detection (Vega and van den 
Berg, 1997; Cannizzaro et al., 2000; Saito and Moffett, 2001; Milne et al., 2010; Shelley et al., 2010). Previous studies have suggested that $D C$ o could be an hybrid-type metal (Bruland and Lohan, 2003; Noble et al., 2008), with a nutrient-like distribution in surface waters (Martin et al., 1993; Saito and Moffett, 2002; Saito et al., 2004; Jakuba et al., 2008; Noble et al., 2008; Saito and Goepfert, 2008; Bown et al., 2011) and a scavenged-type distribution in the deep ocean (Knauer et al., 1982; Wong et al., 1995; Noble et al., 2008; Boyd and Elwood, 2010). Biological uptake by cyanobacteria (Saito et al., 2002), recycling, organic complexation, scavenging and regeneration processes are suspected to strongly impact the distribution of $D C o$ in the surface ocean (Saito and Moffett, 2001, 2002; Noble et al., 2008, 2012; Bown et al., 2011, 2012a). In addition, other important sources of $D C$ o to surface waters, such as river (Tovar-Sanchez et al., 2011) or atmospheric deposition (Shelley et al., 2012), may significantly impact its surface distribution.

In the water column, cobalt and manganese $(\mathrm{Mn})$ often cycle together through a removal pathway of co-oxidation with manganese driven by microbes, but the biological assimilation of $D C$ co can uncouple the Mn-Co relationship in surface waters (Moffett and Ho, 1996). Furthermore, previous studies showed high $D C$ concentrations in oxygendepleted waters (Saito et al., 2004; Pohl et al., 2011; Noble et al., 2012) that can be partly related to slowed microbial oxidation of $D C o$ decreasing its scavenging rate (Noble et al., 2012). On the other hand, the low solubility of inorganic Co in oxygenated waters and the affinity of $D C$ for particles have been invoked to explain why $D C$ does not seem to accumulate in the deep waters along the thermohaline circulation (Bruland and Lohan, 2003) and to interpret the apparent scavenged-type profile of $D C$ o observed in the deep ocean (Aparicio-Gonzalez et al., 2012). In fact, the scavenging of $D C$ onto settling particles and its stabilization in solution by the complexation with organic binding ligands could be the two major pathways controlling the internal cycling of $D C o$ in the deep ocean (Saito and Moffett, 2001, 2002). Those pathways might drive the residence time of $D C$ in the deep waters, estimated $40-120$ years, which is more than two orders of magnitude longer than in surface waters (e.g., 0.32 year; Saito and Moffett, 2002). Hydrothermal vents (Bruland and Lohan, 2003) and sediment resuspension (Bown et al., 2012a) can be the prevailing external sources of $D C$ o to the bottom ocean. In addition, advection of water masses enriched in $D C$, following contact with continental margins, can be a significant source of $D C$ and locally imprints the vertical $D C$ distribution in intermediate and deep waters (Wong et al., 1995; Saito et al., 2004; Noble et al., 2008; Bown et al., 2011, 2012b). Furthermore, large and mesoscale transport of $D C$ Co-enriched waters through the intermediate oceanic circulation has recently been evidenced in the poor-oxygenated Atlantic Central Waters (Noble et al., 2012) and Upper Circumpolar Deep Waters (Bown et al., 2011), as well as close to the Kerguelen Plateau (Bown et al., 2012b). Nevertheless, despite these major findings our understanding of the biogeochemical cycle of cobalt in the ocean is still limited, notably in the western Atlantic Ocean where observations of the deep distribution of $D C$ are scarce.

In this study the vertical and meridional distributions of $D C o$ and apparent particulate cobalt $(P C o)$ are presented along the GEOTRACES-A02 section in the western Atlantic Ocean from the east coast of the Greenland Plateau $\left(64^{\circ} \mathrm{N}\right)$ to the Malvinas Plateau $\left(50^{\circ} \mathrm{S}\right)$. The GEOTRACES-A02 transect is revisiting the Atlantic GEOSECS (Geochemical Ocean Sections) program's section of 1972, crossing distinct biogeochemical areas such as subtropical, equatorial or subpolar domains where different trophic chains are growing in each. Moreover, this section also encounters several water masses involved in the thermohaline circulation and surface jets, such as the North Atlantic Drift, known for its important role in climate regulation. The spatial distributions of $D C o$ and its transportation across the entire deep western Atlantic Ocean are examined. Intercomparison between this data set and others, at three crossover stations located in different biogeochemical domains, are presented. The advection of $D C o$ in the different intermediate and deep water masses flowing in the western Atlantic are studied to further understand its spatial distributions. In addition, the potential effect of the 2010 Icelandic volcano Eyjafjallajökull eruption on the distribution of $D C$ is investigated. We also investigate the role of the remineralization in the distribution of $D C o$ at intermediate depths, and its relationship with phosphate. Finally, the roles of the dynamic structures and the vertical diffusion are considered as they may provide a link between the deep and surface distributions of $D C$. However, the complete description of the cycling and budget of $D C o$ in the surface waters along the GEOTRACES-A02 section will be discussed elsewhere (Dulaquais et al., 2014). This large and deep section together with the relatively high spatial resolution has given us the opportunity to present, for the first time, the largest comprehensive data set of cobalt in the western Atlantic Ocean.

\section{Methods}

\subsection{Cruise track and sampling}

The samples were collected from stations (St.) along the GEOTRACES-A02 section in the western Atlantic Ocean, the longest section of the international GEOTRACES program. Four expeditions conducted between 2010 and 2012 were necessary to complete this section spreading from $64^{\circ} \mathrm{N}$ to $50^{\circ} \mathrm{S}$ along the western Atlantic Ocean (Fig. 1). Three cruises were operated aboard the Dutch R/V Pelagia (legs 1,2,4) and one cruise aboard the British RRS James Cook (leg 3). The first cruise started in April 2010 from $64^{\circ} \mathrm{N}$ to Bermuda in the Sargasso Sea (St. 1-19), followed by the second leg from the station BATS to the Equator (St. 21-41). 


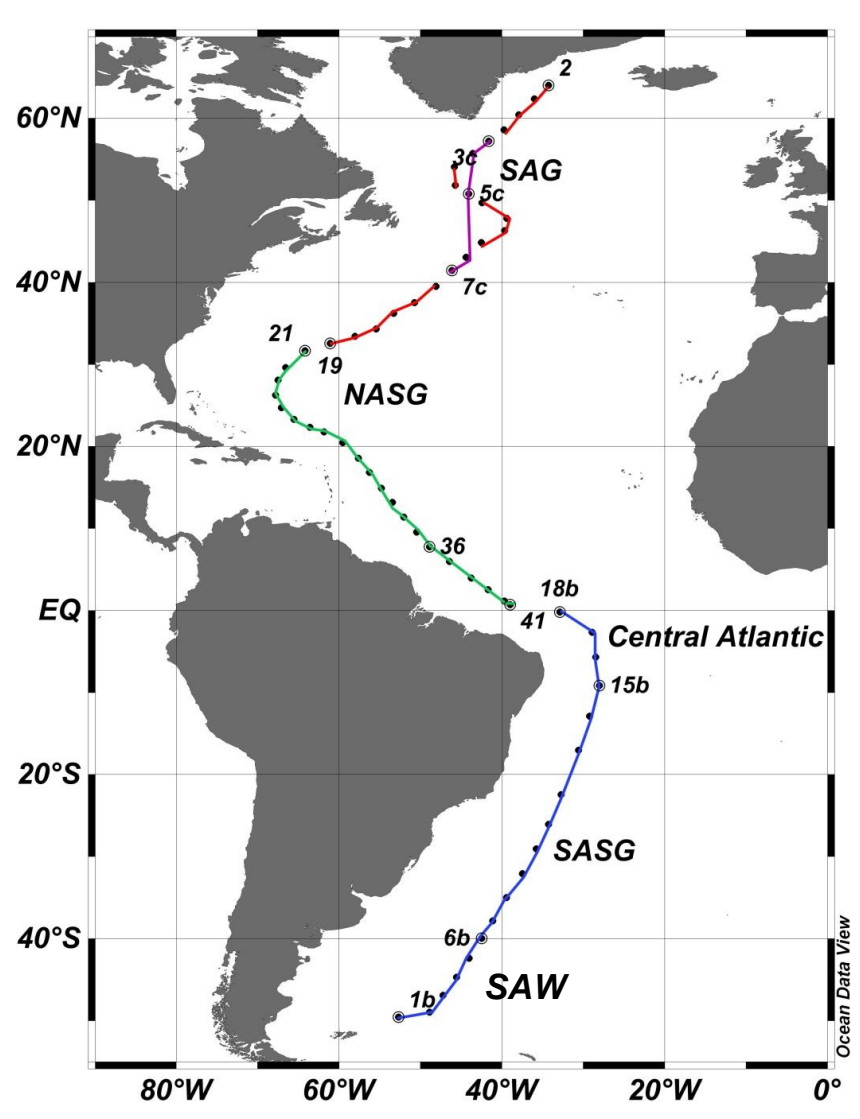

Fig. 1. GEOTRACES-A02 cruises track along the western Atlantic Ocean. Sampling locations of the four legs are shown (leg 1 in red line from station 2 to station 19, leg 2 in green line from station 21 to station 41 , leg 3 in blue line from station $1 \mathrm{~b}$ to $18 \mathrm{~b}$ and leg 4 in purple line from station $3 \mathrm{c}$ to $7 \mathrm{c}$ ).

The section in the southwestern Atlantic (leg 3) from $50^{\circ} \mathrm{S}$ to the Equator was achieved in March 2011 (St. 1b-18b). An additional cruise (leg 4) was operated in August 2012 to complete the first leg that had been fragmented due to bad weather (St. 3c-7c).

A total of 47 stations with a vertical resolution of 1216 depths between $9 \mathrm{~m}$ and $5930 \mathrm{~m}$ were sampled for dissolved cobalt analyses ( $D C$ Co), and 15 stations for total (unfiltered) cobalt determinations $(T C O)$. The apparent particulate cobalt concentrations $(P C)$ were calculated by substraction of $D C$ from $T C o$. The complete data set of cobalt (dissolved, total, and apparent particulate) at all stations will be available at the international GEOTRACES data center (http://www.bodc.ac.uk/geotraces/).

Samples were taken using the TITAN-CTD frame of NIOZ (Netherlands), with 24 ultra-clean 24.4 L sampling bottles made of PVDF (polyvinylidene fluoride) plastic (de Baar et al., 2008). The frame was placed in a Class- 100 container for sub-sampling (de Baar et al., 2008). Unfiltered samples were transferred into acid-cleaned $250 \mathrm{~mL}$ Nalgene ${ }^{\mathrm{TM}}$ LDPE (low-density polyethylene) bottles for
$T C o$ analyses. The samples for $D C o$ analyses were collected after filtration using $0.2 \mu \mathrm{m}$ Sartobran ${ }^{\mathrm{TM}} 300$ (Sartorius) cartridges under pure $\mathrm{N}_{2}$ pressure (filtered $99.99 \% \mathrm{~N}_{2}, 0.7 \mathrm{~atm}$ ) in acid-cleaned $250 \mathrm{~mL}$ or $500 \mathrm{~mL}$ Nalgene ${ }^{\mathrm{TM}}$ LDPE bottles. All samples were acidified at $\mathrm{pH} \sim 2$ using ultrapure $\mathrm{HCl}^{\mathrm{TM}}$ (Merck) immediately after their collection. Then the acidified samples were dark-stored in double bags at ambient temperature in preparation of their analyses in the shore-based laboratory.

\subsection{Analytical method for cobalt analyses}

\subsubsection{Method}

Prior to the analyses, the samples were UV-digested (Saito and Moffet, 2002; Shelley et al., 2010) for $3 \mathrm{~h}$ in acid-cleaned silica tubes using a $600 \mathrm{~W}$ high-pressure mercury vapor lamp (Bown et al., 2011), and left for an equilibration time of $48 \mathrm{~h}$. Preliminary tests indicated that $3 \mathrm{~h}$ of UV-digestion were required to fully recover Co in surface and deep samples (data not shown).

Dissolved and total cobalt concentrations were determined by flow-injection analysis (FIA) and chemiluminescence detection following the method adapted from Shelley et al. (2010), as described in Bown et al. (2011). In this method, cobalt catalyzes the oxidation reaction of pyrogallol with hydrogen peroxide in an alkaline solution in the presence of cetyltrimethylammonium bromide (CTAB) and methanol. A chemiluminescent emission in the visible wavelengths proportional to the cobalt concentration is produced during this reaction. The system consists of one 10-port injection valve (VICI valves from VALCO instruments), which operates as an autosampler, and of two micro-electronically actuated injection valves (VICI valves from VALCO instruments) that use Tygon ${ }^{\circledR}$ tubes to inject the sample and the reagents. The flow injection is provided by a peristaltic pump (205 CA, Watson Marlow).

The reagents were prepared with trace metals quality reagents, as described in Bown et al. (2011). All reagents were prepared under a laminar flow hood (ADS Laminaire, ISO 5 class) in $1 \mathrm{~L}$ LDPE Nalgene ${ }^{\circledR}$ bottles with ultrapure water (MiliQ, $18.2 \mathrm{M} \Omega$ ) the day before the analysis and kept at room temperature for an overnight equilibration.

The sample was buffered online with ammonium acetate (0.3 M, ACS Reagents) and loaded onto an IDA-Toyopearl chelating resin to preconcentrate the cobalt contained in the sample. Then a $\mathrm{HCl}$ solution $\left(0.1 \mathrm{M}\right.$, Suprapur ${ }^{\circledR}$ Merck) was injected through the column to elute Co. The eluent was warmed in a $60^{\circ} \mathrm{C}$ thermostatic bath to limit the interferences in the detection system due to bubbles (Shelley et al., 2010). The detection system consisted of a photomultiplier detector (Hamamatsu, H9319 series). The injection valves and the photomultiplier detector were operated on a laptop by a modified Labview ${ }^{\circledR} 8.4$ interface (E. Duvieilbourg and M. Boye, 
LEMAR). The electrical devices were connected to a modulator of current (ELLIPSEMAX 600, MGE/UPS Systems).

The Co concentrations were calibrated against two calibration curves made with standard additions of cobalt of 0 , $12.5,25,50,75$ and $100 \mathrm{pM}$ to seawater, and performed before and after each series of 8 or 12 samples. $T$ Co and $D C o$ concentrations were based on triplicate analyses of each sample using the mean peak height of the chemiluminescent signal, and corrected with respect to blank analyses. Two to four reagent blanks, including the buffer blank, were analyzed per series of 8-12 samples at the beginning and at the end of the series in acidified MilliQ water instead of the sample (Bowie and Lohan, 2009; Bown et al., 2011).

The final standard deviation of the measurement was calculated by an error propagation using the error on blanks, the calibration curves and the deviation of the triplicate analyses. The paired two-tailed $t$ test shows that the differences between $T C$ and $D C o$ (e.g., equivalent to apparent particulate Co) are statistically significant at the $95 \%$ confident interval $\left(P<0.05, t_{\text {critical }}=2.84, t_{\text {experimental }}=12.83\right.$, $n=203$ ), allowing reliable estimation of $P$ Co concentration. The standard error on $P C o$ was calculated by combining uncertainties of $D C o$ and $T C o$ measurements (e.g., $\left.\mathrm{SD}_{P \mathrm{Co}}=\left(\mathrm{SD}_{D \mathrm{Co}}^{2}+\mathrm{SD}_{T \mathrm{Co}}^{2}\right)^{0.5}\right)$.

\subsubsection{Analytical performance}

The mean reagent blank (based on all blank determinations) was $4.2 \pm 2.1 \mathrm{pM}(n=180)$ of Co in MilliQ $(n=180)$. The limit of detection of the method estimated as three times the standard deviation of the mean reagent blank was $6.3 \mathrm{pM}$ $(n=180)$. Each series of samples was calibrated by running one or two samples collected during the "Sampling and Analysis of iron" (SAFe) program or GEOTRACES program. SAFe and GEOTRACES samples were UV-digested for $3 \mathrm{~h}$ prior to analysis and the results of $D C$ concentrations are reported in Table 1 . The DCo concentrations we measured in the SAFe and GEOTRACES referencesamples are in excellent agreement with the consensus values (http://www.geotraces.org/science/intercalibration/ 322 -standards-and-reference-materials). The $D C$ co value obtained in the S-SAFe sample also falls in the consensus value despite the concentration being lower than the detection limit. The analytical precision of the method was determined from repeated analyses of the surface S-GEOTRACES reference sample, yielding an uncertainty of $\pm 3.8 \%$ expressed as relative standard deviation on the mean $(n=15)$.

\subsection{Hydrography}

Hydrological parameters $\left(S, T^{\circ}, \mathrm{O}_{2}\right.$, conductivity, fluorescence and turbidity) were measured using an SBE9+ underwater sensor, an SBE3+ thermometer $\left( \pm 0.001^{\circ} \mathrm{C}\right)$, an SBE4 conductivity sensor $\left( \pm 0.3 \mathrm{mS} \mathrm{s}^{-1}\right)$, an SBE43 dissolved oxygen sensor $( \pm 2 \%)$, a Chelsea Aquatracka MKIII
Table 1. Comparison of dissolved cobalt analyses obtained in the UV-oxidized samples by the FIA-chemiluminescence method used in the present study with consensus values reported by the Sampling and Analysis of iron (SAFe) and GEOTRACES programs. Water samples provided by SAFe and GEOTRACES from surface waters (SAFe S and GEOTRACES S) and deep waters (SAFe D1 and D2, and GEOTRACES D) were analyzed. Errors are given as standard deviation from average values.

\begin{tabular}{lll}
\hline Sample & $D$ Co measured $(\mathrm{pM})$ & $\begin{array}{l}\text { Consensus } \\
\text { value }(\mathrm{pM})\end{array}$ \\
\hline SAFe S & $5.1 \pm 2.2(n=25)$ & $4.8 \pm 1.20$ \\
SAFe D1 & $42.3 \pm 1.4(n=15)$ & $45.4 \pm 4.7$ \\
SAFe D2 & $44.2 \pm 1.7(n=25)$ & $45.7 \pm 2.9$ \\
GEOTRACES S & $29.8 \pm 2(n=35)$ & $31.8 \pm 1.1$ \\
GEOTRACES D & $63.2 \pm 2.3(n=25)$ & $65.2 \pm 1.2$ \\
\hline
\end{tabular}

fluorometer $\left( \pm 0.2 \mu \mathrm{gl}^{-1}\right)$, and a Wetlabs C-Star transmissometer $\left( \pm 0.02 \%{ }^{\circ} \mathrm{C}^{-1} ; 25 \mathrm{~cm}\right.$, deep, red $)$.

\subsection{Macronutrients analysis}

Nutrient samples were collected in $125 \mathrm{~mL}$ polypropylene bottles using a CTD-rosette (Seabird ${ }^{\circledR}$ ) equipped with Niskin bottles. The analyses were performed on board from surface to deep waters samples. All the nutrients were analyzed by colorimetric methods, following the methods of Murphyand Riley (1962) for phosphate $\left(\mathrm{HPO}_{4}^{2-}\right)$, of Strickland and Parsons (1968) for silicate $\left(\mathrm{Si}(\mathrm{OH})_{4}^{-}\right)$, and of Grasshoff et al. (1983) for nitrate $\left(\mathrm{NO}_{3}^{-}\right)$and nitrite $\left(\mathrm{NO}_{2}\right)$.

\section{Results}

\subsection{Circulation and dynamic structures}

In the North Atlantic, the section crosses the subarctic gyre (SAG) between $64^{\circ} \mathrm{N}$ and $50^{\circ} \mathrm{N}$, where the Labrador Sea Water (LSW) dives to form with the Arctic Bottom Water, the Western North Atlantic Deep Water (WNADW). Deeper, the Eastern North Atlantic Deep Water (ENADW) is also isolated in the SAG and forms, further south, with the WNADW the North Atlantic Deep Water (NADW) (Fig. 2). The welloxygenated and dense waters of the subarctic gyre are separated, in the south, from relatively low-oxygenated, saline and warm waters of the North Atlantic subtropical gyre (NASG) by the North Atlantic subtropical front (NSTF) at $\sim 45^{\circ} \mathrm{N}$. The NSTF is characterized by a high anomaly of temperature $\left(+5^{\circ} \mathrm{C}\right)$ and by a strong eastward geostrophic current in surface waters (data not shown) which is likely to be the North Atlantic Drift (Reid, 1994).

In the NASG, low-density waters occur in the top $600 \mathrm{~m}$ due to relatively high salinity and temperature $\left(T^{\circ}>10^{\circ} \mathrm{C}\right.$; $S>35$ ) (Fig. 2). However, at $15^{\circ} \mathrm{N}$ and, to a lesser extent, at $4^{\circ} \mathrm{N}$ these saline waters are covered by relatively fresh 

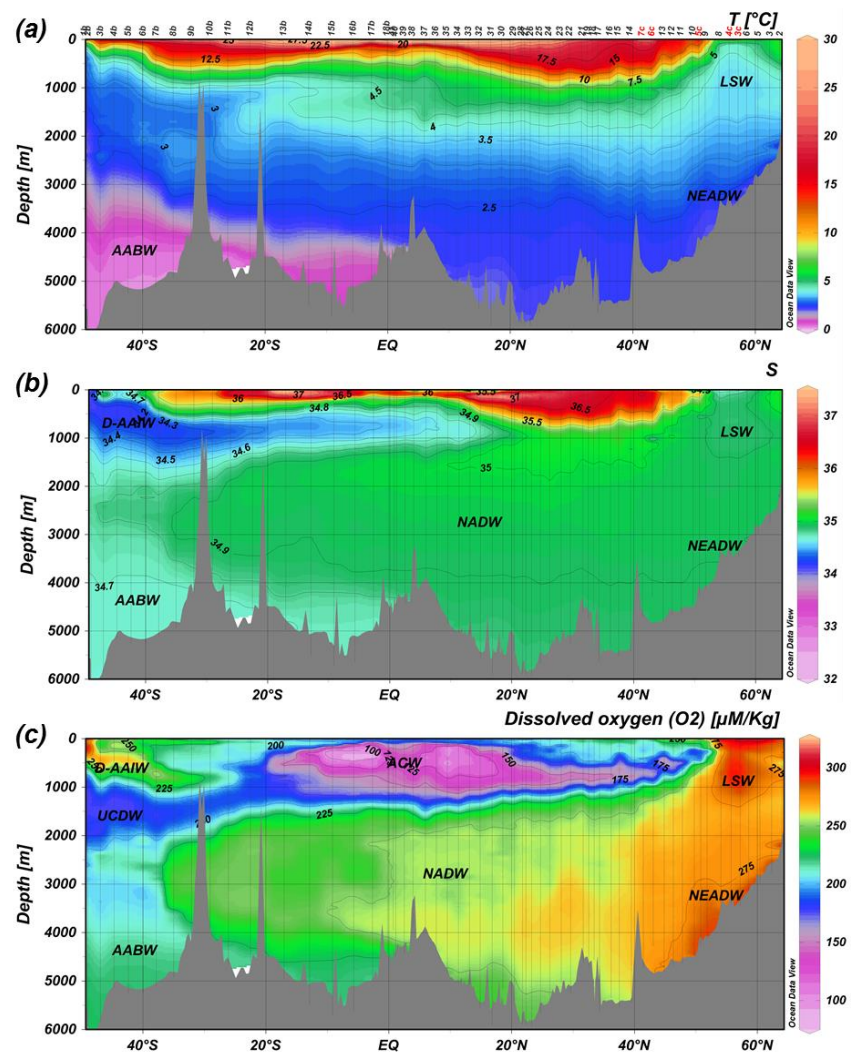

Fig. 2. Interpolated vertical sections of (a) temperature $(T)$, (b) salinity $(S)$ and (c) dissolved oxygen $\left(\mathrm{O}_{2}\right)$ along the GEOTRACES-A02 section in the western Atlantic, based on CTD data. The different water masses - LSW, NEADW, NADW, ACW, AABW, D-AAIW and UCDW - are identified by their physical features and are indicated in the figure panels. Stations sampled during leg 4 are labeled in red.

waters (Fig. 2) originating from the Amazon plume. The waters influenced by the Amazon plume are characterized by a relatively high $\mathrm{Si}: \mathrm{N}$ ratio and turbidity (data not shown).

Leaving the NASG southwards, the section enters into the equatorial area (EA). Here, the zonal geostrophic velocities indicate the presence of several jets near the surface, such as the North Equatorial Current (NEC, at 5-10 $\mathrm{N}$ ), the North Equatorial Countercurrent $\left(\mathrm{NECC}\right.$, at $\left.\sim 3^{\circ} \mathrm{N}\right)$, the South Equatorial Current (SEC, at $5-10^{\circ} \mathrm{S}$ ) and the South Equatorial Undercurrent (SEUC, at $\sim 5^{\circ} \mathrm{S}, 200 \mathrm{~m}$ depth), as described by Peterson and Stramma (1991). The equatorial domain is bordered by the NEC in the north and by the SEC in the south, both of which are characterized by westward surface geostrophic propagating vectors of correlating speeds (respectively 0.2 and $0.15 \mathrm{~m} \mathrm{~s}^{-1}$ ). Below $100 \mathrm{~m}$, the salinities and temperatures are lower than in the NASG, revealing denser waters. An oxygen minimum zone (OMZ; $\left.\mathrm{O}_{2}<150 \mu \mathrm{M}\right)$ was also observed under these surface currents, between 150 and $600 \mathrm{~m}$ (Fig. 2c). Part of this low $\mathrm{O}_{2}$ signature was due to the advection of the poor-oxygenated
Atlantic Central Waters $\left(\mathrm{O}_{2}<50 \mu \mathrm{M}\right.$; Noble et al., 2012), flowing westward from the African border across the Atlantic basin.

Southward, the section enters into the South Atlantic subtropical gyre (SASG) characterized, like in the North Atlantic, by low-density waters associated with relatively high salinities and temperatures (Fig. 2a and b). Despite strong eddy activity in this area, clearly observed in the geostrophic current field, the Malvinas-Brazil confluence (MBC), an eastward jet resulting from the Brazil current flowing southward and the Malvinas current flowing northward, can be located in the Argentine basin around $40^{\circ} \mathrm{S}$ (e.g., at station $6 \mathrm{~b}$; data not shown). The MBC separates the SASG with saline and relative oxygen-poor waters from the subantarctic waters (SAW).

Several water masses involved in the large-scale ocean circulation were characterized by depth (Fig. 2). For instance, the LSW was characterized by $34.9<S>34.8$ and $\mathrm{O}_{2}>275 \mu \mathrm{mol} \mathrm{kg}{ }^{-1}$ in the subarctic gyre at $60^{\circ} \mathrm{N}$ (Fig. 2). The ENADW $(S>34.925)$ circulates underneath the LSW, following the topography below $2500 \mathrm{~m}$ in the northern side of the section. The core of the ENADW is situated between $62^{\circ} \mathrm{N}$ and $45^{\circ} \mathrm{N}$. The WNADW and the ENADW both form the NADW, spreading southward into the deep ocean from $60^{\circ} \mathrm{N}$ to $37^{\circ} \mathrm{S}$ (Tomczak and Godfrey, 2003). The Antarctic Bottom Water (AABW), characterized by $S<34.8$ and $T^{\circ}<1^{\circ} \mathrm{C}$, is formed in the Weddell Sea (Reid, 1989; Gladyshev et al., 2008) and spreads at the bottom of the ocean below $4000 \mathrm{~m}$. The AABW enters the Atlantic Ocean by the south and follows the topography until $3^{\circ} \mathrm{N}$. To the north the bottom waters are a mix between AABW, Arctic Bottom Waters (ABW) and NADW (Tomczak and Godfrey, 2003). In the Southern Hemisphere, the relatively fresh Antarctic Intermediate Waters entering from the Drake Passage (D-AAIW; $S>34.2$ ) are identified at intermediate depths between 500 and $1000 \mathrm{~m}$. Finally, the oxygen distribution enables us to distinguish the different components of the Circumpolar Deep Waters (CDW; Whitworth and Nowlin, 1987), with its upper component (UCDW) at about $1500 \mathrm{~m}$, marked by $\mathrm{O}_{2}<190 \mu \mathrm{mol} \mathrm{kg}-1$, and its intermediate component (ICDW) at about $2500 \mathrm{~m}$ with $\mathrm{O}_{2}>210 \mu \mathrm{mol} \mathrm{kg}^{-1}$ (Fig. 2c). The intermediate waters in the equatorial domain are formed by a mix of AAIW and UCDW that both flow northward and of the Atlantic Central Waters (ACW) originated from the east Atlantic basin (Poole and Tomczak, 1999). However, it has to be noted that the transitions between the different water masses vary with the latitude (Fig. 2).

\subsection{The nutrients distribution along the GEOTRACES- A02 section}

Different biogeochemical domains were characterized in surface waters along the GEOTRACES-A02 section (Fig. 3). The surface waters of the SAG were marked by relatively 

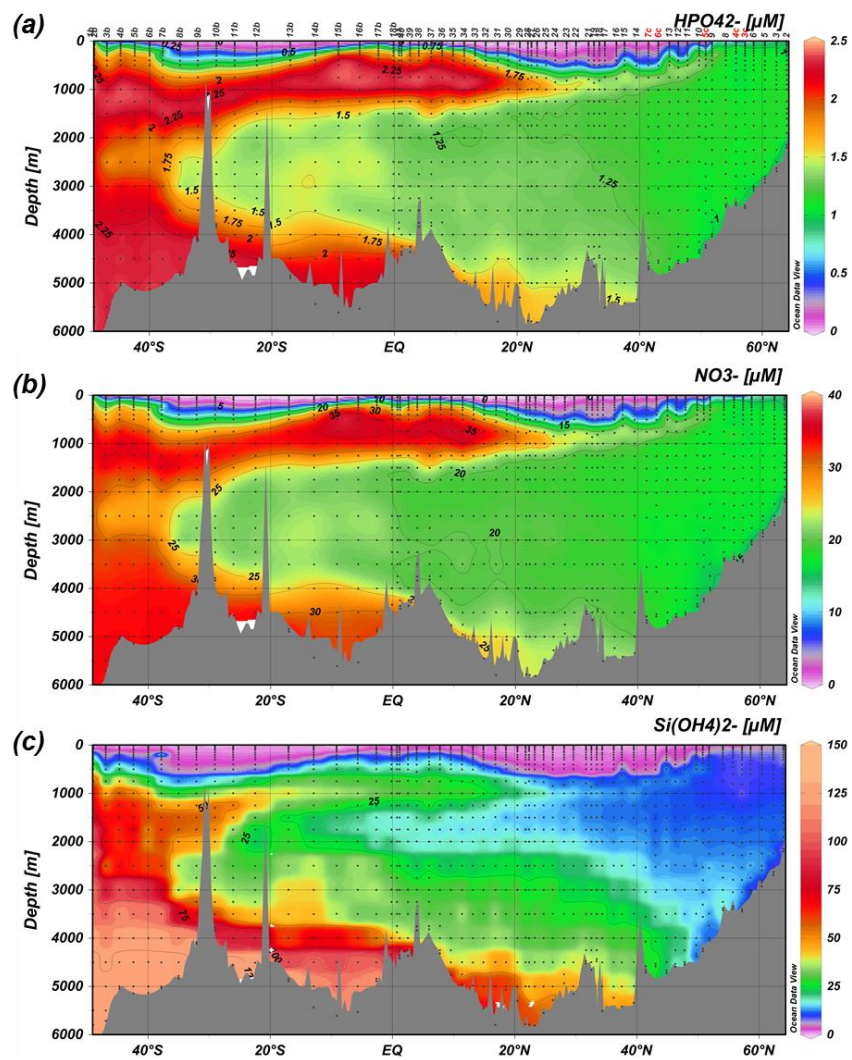

Fig. 3. Interpolated vertical sections of (a) phosphate, (b) nitrate and (c) silicate based on 1440 analysis of water-column samples collected and measured by NIOZ along the Netherlands area of GEOTRACES-A02 section. Stations sampled during leg 4 are labeled in red.

high phosphate and nitrate concentrations $\left(\mathrm{NO}_{3}>10 \mu \mathrm{M}\right.$; $\mathrm{PO}_{4}>0.8 \mu \mathrm{M}$; Fig. 3). In the two subtropical domains, the extremely low nutrients concentrations (such as observed in the NASG where $\mathrm{PO}_{4}<0.5 \mu \mathrm{M}, \mathrm{NO}_{3}<5 \mu \mathrm{M}, \mathrm{Si}<5 \mu \mathrm{M}$ ) were characteristic of oligotrophic conditions. However, a greater depletion of nitrogen relative to phosphate was observed in the upper $300 \mathrm{~m}$ of the SASG $(\mathrm{N}: \mathrm{P}<10)$ compared to the NASG $(\mathrm{N}: \mathrm{P}>25)$, probably due to a greater proportion of $\mathrm{N}_{2}$ fixers, such as diazotrophic cyanobacteria, in the NASG than in the SASG (Mather et al., 2008). In the equatorial area, the intermediate waters were characterized by relatively high concentrations of nitrate and phosphate $\left(\mathrm{NO}_{3}>34 \mu \mathrm{M}, \mathrm{PO}_{4}>2.3 \mu \mathrm{M}\right)$, whereas silicate concentrations were low $(5 \mu \mathrm{M}<\mathrm{Si}<15 \mu \mathrm{M})$, suggesting the incursion of D-AAIW formed in the southwestern Atlantic. South of the south subtropical front, the nutrients distribution showed, as for oxygen, the influence of the AAIW and UCDW with relatively high nutrients concentration in the top $200 \mathrm{~m}$ depths $\left(\mathrm{NO}_{3}>20 \mu \mathrm{M}, \mathrm{PO}_{4}>1.2 \mu \mathrm{M}\right)$. In the deep ocean the nutrients distribution reflected a combination of aging and advection of water masses (Fig. 3). The spreading of young NADW can be followed with the low-nutrients signature $\left(\mathrm{Si}<35 \mu \mathrm{M} ; \mathrm{NO}_{3}<20 \mu \mathrm{M} ; \mathrm{PO}_{4}<1.5 \mu \mathrm{M}\right)$. Phosphate and nitrate concentrations increased southward in the deep ocean (Fig. 3) due to mixing of Arctic waters (poor in nutrients) with nutrients-enriched Antarctic waters. The AABW was characterized by relatively high nutrients concentration $\left(\mathrm{Si}>130 \mu \mathrm{M} ; \mathrm{NO}_{3}>30 \mu \mathrm{M} ; \mathrm{PO}_{4}>2 \mu \mathrm{M}\right)$, which decreased northward. The nutrients concentration in the Circumpolar Deep Waters was similar to those of AABW, but the concentrations in the ICDW were a little bit lower than those in the UCDW. The silicate levels are depleted in the AAIW compared to other Antarctic waters.

\subsection{The comprehensive distribution of cobalt in the western Atlantic}

The meridional and vertical distributions of $D C$ along the GEOTRACES-A02 section are presented in Fig. 4a. Dissolved cobalt concentrations range from $14.72 \pm 1.43$ to $93.27 \pm 3.31 \mathrm{pM}$ along the section. The lowest concentration was observed in surface waters of the SASG (e.g., at $9 \mathrm{~m}$ depth at St. $11 \mathrm{~b}-26^{\circ} \mathrm{S}$ ), whereas the highest were recorded in the OMZ of the equatorial area (e.g., at St. 15b $-9^{\circ} \mathrm{S}$ at $290 \mathrm{~m}$ depth). The vertical distributions of the apparent particulate cobalt concentrations $(P \mathrm{Co})$ are presented in Fig. 4b. The apparent particulate cobalt concentrations ranged from near undetectable values (e.g., the difference between unfiltered and filtered samples analyses is nearly null) to $18.85 \pm 3.97 \mathrm{pM}$ (e.g., at St. $17-34.3^{\circ} \mathrm{N}$ at $5510 \mathrm{~m}$ depth). The $P C \mathrm{Co} / D C$ ratio ranged from $0.06 \%$ (St. $17 ; 2500 \mathrm{~m}$ ) to $44 \%$ (St. 26, $25 \mathrm{~m}$ ), with a mean of $7 \%$ $(n=192)$.

Different vertical distributions of $D C$ co were observed in each biogeochemical domain (Figs. 4 and 5). The distribution of $D C$ o showed an apparent scavenged-like profile in the northern subarctic gyre (Figs. 4a-5a), with relatively higher concentrations in surface waters $\left(D C o_{\text {upper }} 200 \mathrm{~m}>\right.$ $70 \mathrm{pM})$ compared to deeper waters $\left(D C\right.$ obelow $_{2000 \mathrm{~m}<}$ $60 \mathrm{pM})$. In this domain, lower surface $D C$ co concentrations were recorded in 2012 during leg 4 (e.g., $42.1 \pm 2.15 \mathrm{pM}$ at St. $3 c$, and $44.23 \pm 1.26 \mathrm{pM}$ at St. $4 \mathrm{c}$, at $25 \mathrm{~m}$ depth) compared to those observed in 2010 during leg 1 (e.g., mean $D C o=64.56 \pm 5.25 \mathrm{pM}$ at $25 \mathrm{~m}(n=4)$, with a $D C o$ maximum of $68.2 \pm 1.08 \mathrm{pM}$ at St. 5). At intermediate depths $(500-1000 \mathrm{~m})$, the LSW was characterized by relatively high $D C o$ concentrations ( $D C o \sim 70 \mathrm{pM}$ ) compared to those found in the ENADW ( $D C o \sim 55 \mathrm{pM}$ below $2000 \mathrm{~m}$ ). In this domain, the apparent particulate cobalt distribution showed relative $P C o$ maxima in the subsurface (ranging from $5.9 \pm 1$ to $10.4 \pm 1.96 \mathrm{pM}$ ), and decreasing concentrations with depth (until undetectable levels around $1500 \mathrm{~m}$ depth). Maxima of $P C o(>10 \mathrm{pM})$ were then observed near the bottom (at St. 2 and 11).

In contrast, $D C$ Co was depleted in the surface waters of the two subtropical domains and increased with depth below the nutricline, featuring a nutrient-like distribution 

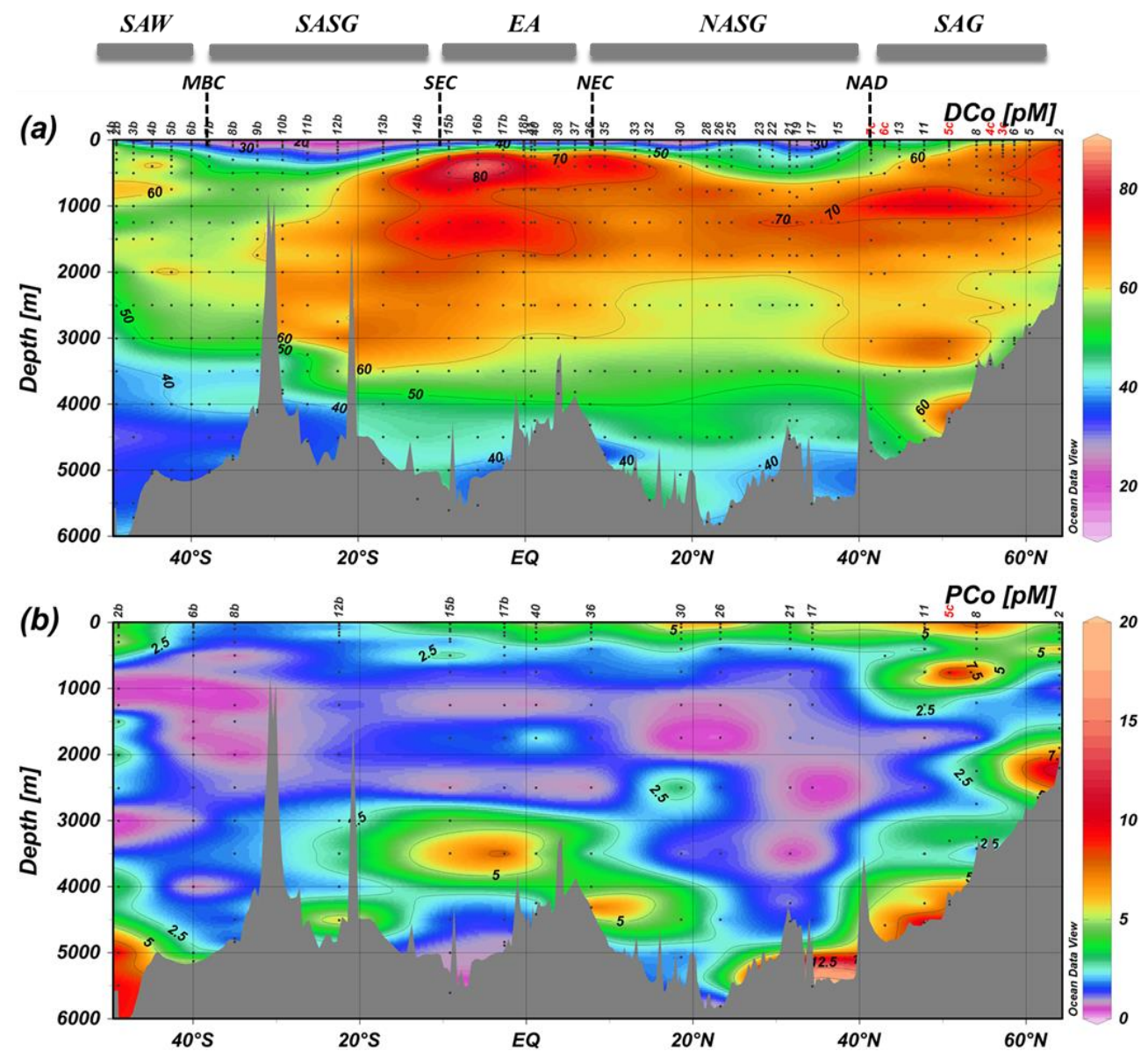

Fig. 4. Interpolated vertical sections of (a) dissolved cobalt ( $D C \mathrm{co}, \mathrm{pM})$ and (b) apparent particulate cobalt $(P C o, \mathrm{pM})$ based on 675 analyses for $D C$ and 203 analyses for $P C$ a along the GEOTRACES-A02 section in the western Atlantic. Stations sampled during leg 4 are labeled in red. The domains of SAG, NASG, EA, SASG and SAW are characterized by the macronutrients concentrations and by the surface currents (e.g., NAD, NEC, SEC, and MBA).

(Figs. 4a-5b). However, DCo are slightly lower and shallower in the SASG (mean $D C$ co value of $23.01 \pm 4.17 \mathrm{pM}$, $n=9$ ) compared to those found in the NASG (mean DCo value of $28.8 \pm 4.8 \mathrm{pM}, n=15$ ). Subsurface relative maxima of $D C$ o were observed at about $10 \mathrm{~m}$ depth at a few stations in the NASG. Deep relative $D C$ o maxima were also observed at around 1250-1750 m depth in the NASG, which are in the core of NADW and below the oxygen minima. On the contrary, relative $D C$ maxima and oxygen minima were often located at the same depth in the SASG, within the core of the mixed NADW. In the AABW of the SASG, $D$ Co was on average equal to $42.8 \pm 2.23 \mathrm{pM}(n=$ $15)$. In the two subtropical gyres, the $P C o$ concentrations ranged from undetectable value (e.g., at $2500 \mathrm{~m}$ of St. 17) to $18.85 \pm 3.97 \mathrm{pM}\left(\right.$ at $\left.5510 \mathrm{~m}-34.3^{\circ} \mathrm{N}\right)$. Like in the northern latitudes, relatively high $P C$ co concentrations were observed in the surface waters, decreasing with depth, and increasing again near the seafloor (Fig. 5e). The $P$ Co distribution also showed, like $D C$, relatively lower $P C$ co concentrations in the subsurface waters of the SASG $(<5 \mathrm{pM})$ compared to the NASG $(>5 \mathrm{pM})$.

In the equatorial area, the $D C$ distribution was characterized by low concentrations in the top $100 \mathrm{~m}$ (mean $\left.D \mathrm{Co}_{100 \mathrm{~m}}=29.6 \pm 9 \mathrm{pM}, n=44\right)$, a sharp increase between 100 and $250 \mathrm{~m}$ (mean $D \mathrm{Co}_{\int 100-250 \mathrm{~m}}=61.7 \pm 13 \mathrm{pM}$, $n=10$ ), which continued to increase, reaching maximum values at about $400 \mathrm{~m}$ depth (mean $D \mathrm{Co}_{\int 250-400 \mathrm{~m}}=$ $73.2 \pm 10 \mathrm{pM}, n=19$ ) (Figs. $4-5 \mathrm{c}$ ). These maximum concentrations were the highest values recorded along the section and reached values up to $93.27 \pm 3.31 \mathrm{pM}$ (at $9^{\circ} \mathrm{S}$ ). Furthermore, these $D C$ maxima strongly correlated with the oxygen depletion $\left(\triangle D C \mathrm{Co} / \Delta \mathrm{O}_{2}=-0.28 \mu \mathrm{M} \mathrm{M}^{-1}, R^{2}>\right.$ $0.66 ; n=57 ; P<0.05)$. Between 1000 and $2500 \mathrm{~m}$ depth, the $D C$ concentrations were in the same range as those observed at $100-250 \mathrm{~m}$ depths (mean $D \mathrm{Co}_{\int} 1000-2500 \mathrm{~m}=$ $67.6 \pm 5.8 \mathrm{pM}, n=33)$. Deeper $D C$ concentrations decreased to a mean value of $41 \pm 4 \mathrm{pM}(n=15)$ below $4000 \mathrm{~m}$. The distribution of $P C o$ in the equatorial domain 


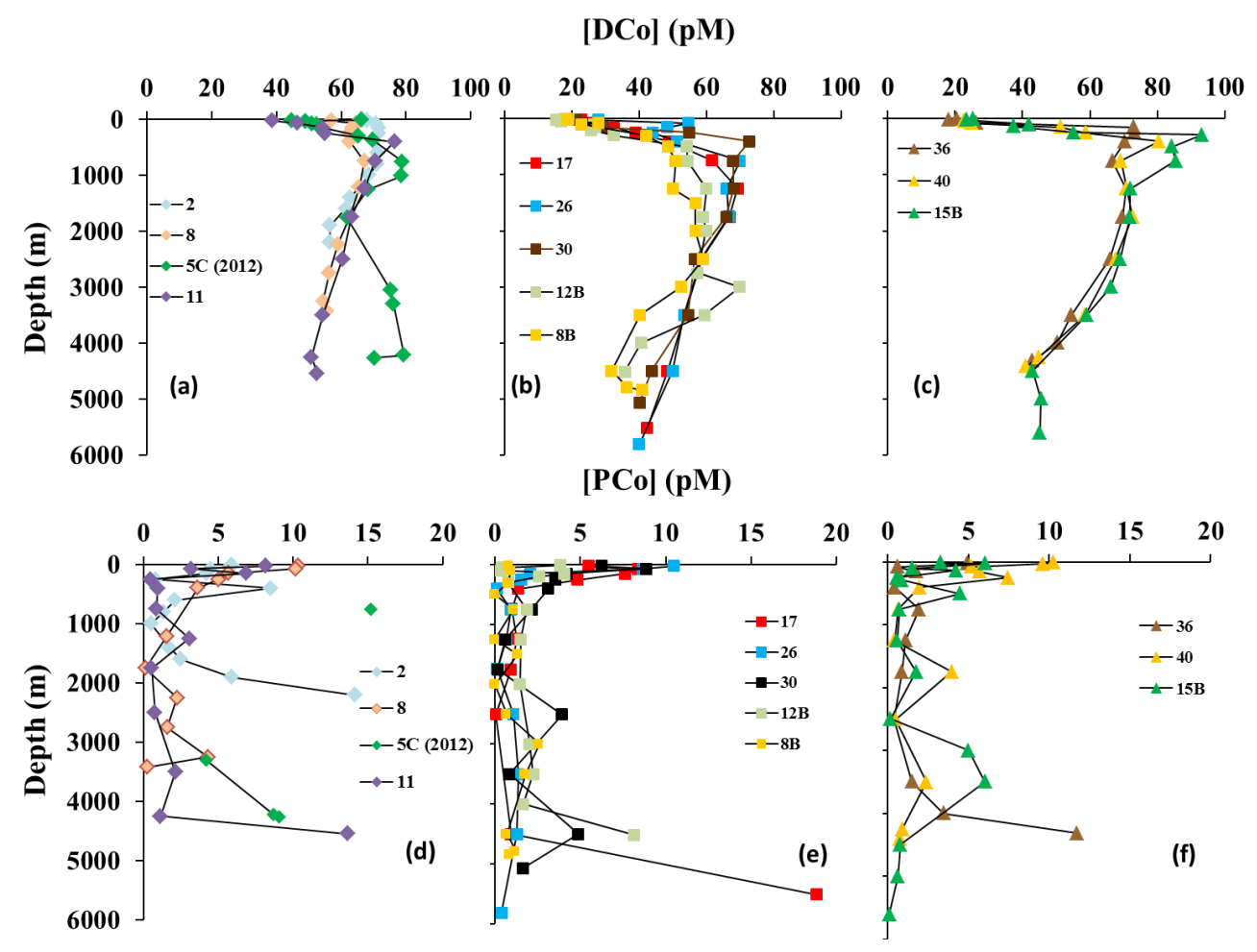

Fig. 5. Typical vertical distribution of dissolved $(D C o)$ and apparent particulate $(P C o)$ cobalt against depth in the different biogeochemical domains: in the SAG, DCo (a) and PCo (d) are shown for Station $2\left(64^{\circ} \mathrm{N}, 34.25^{\circ} \mathrm{W}\right)$, St. $8\left(54^{\circ} \mathrm{N}, 45.84^{\circ} \mathrm{W}\right) \mathrm{St} .5 \mathrm{c}\left(50^{\circ} \mathrm{N}, 44^{\circ} \mathrm{W}\right)$ and St. $11\left(48^{\circ} \mathrm{N}, 39.4^{\circ} \mathrm{W}\right)$; in the north and south subtropical domains $D C$ o (b) and $P$ Co (e) are shown at St. $17\left(34.3^{\circ} \mathrm{N}, 55.4^{\circ} \mathrm{W}\right)$, St. 26 $\left(23^{\circ} \mathrm{N}, 65.55^{\circ} \mathrm{W}\right)$, St. $30\left(18.5^{\circ} \mathrm{N}, 57.6^{\circ} \mathrm{W}\right)$, St. $12 \mathrm{~b}\left(22.47^{\circ} \mathrm{S}, 32.7^{\circ} \mathrm{W}\right)$ and St. $8 \mathrm{~b}\left(35^{\circ} \mathrm{S}, 39.4^{\circ} \mathrm{W}\right)$; and in the equatorial area $D C$ co $(\mathbf{c})$ and $\mathrm{PCo}(\mathbf{f})$ are presented at St. $36\left(7.8^{\circ} \mathrm{N}, 48.9^{\circ} \mathrm{W}\right)$, St. $40\left(1^{\circ} \mathrm{N}, 39.7^{\circ} \mathrm{W}\right)$ and St. $15 \mathrm{~b}\left(9^{\circ} \mathrm{S}, 28^{\circ} \mathrm{W}\right)$.

was similar to that observed in the other domains, with several extremely low (undetectable) values in deep waters and relatively higher concentrations $(P C o>5 \mathrm{pM})$ in surface waters, up to a maximum value of $10.24 \pm 2.1 \mathrm{pM}$ observed at $10 \mathrm{~m}$ at St. $40\left(1.15^{\circ} \mathrm{N}\right)$. A different pattern was, however, observed in the deep waters at $8^{\circ} \mathrm{N}$ (St. 36), where significant and increasing $P$ Co concentrations were detected between $3500 \mathrm{~m}(1.52 \pm 0.7 \mathrm{pM})$ and $4315 \mathrm{~m}(11.73 \pm 1.9 \mathrm{pM})$, as well as at $3^{\circ} \mathrm{S}$ (St. 17b) where extremely high $P$ Co concentrations were measured at $3500 \mathrm{~m}$ depth $(12.53 \pm 2.4 \mathrm{pM})$. In the surface waters, high $P$ Co concentration $(\sim 10 \mathrm{pM})$ was detected at $1^{\circ} \mathrm{N}$ (St. 40) in the Amazon plume.

In the area of the Brazil-Malvinas confluence, DCo increased southward in the surface waters. The vertical distribution showed the highest $D C$ concentrations in the core of D-AAIW (100-600 m; Fig. 4a), whereas DCo levels decreased in deeper waters, generating an apparent scavengedtype distribution at latitudes of $49-49.5^{\circ} \mathrm{S}$ (St. 1b-2b). The $D C o$ concentrations observed in the youngest AABW flowing in this area were the lowest values recorded in the core of the AABW along the section $(D C o \quad 4000-6000 \mathrm{~m}=$ $34.9 \pm 3 \mathrm{pM}$ ). Only one profile of $P$ Co has been obtained in this area at $49^{\circ} \mathrm{S}$ (St. 2b). It showed relatively high $P$ Co concentrations in the upper $300 \mathrm{~m}(P \mathrm{Co}>6 \mathrm{pM})$, and, as for the other domains, undetectable $P$ Co concentrations in deepwaters, except at $5000 \mathrm{~m}$ where $P C o$ reached a maximum $(11.8 \pm 3.4 \mathrm{pM})$.

\section{Discussion}

\subsection{Comparison of data sets of dissolved cobalt concentrations obtained at three crossover stations}

Three crossover stations were occupied along the GEOTRACES-A02 section, at the Bermuda Atlantic Time Series BATS station $\left(64.17^{\circ} \mathrm{W}, 31.7^{\circ} \mathrm{N}\right)$, at $9^{\circ} \mathrm{S}$ during the US CoFeMUG cruise in 2007 , and at $40^{\circ} \mathrm{S}$ during the English GEOTRACES-A10 section in 2012 (Fig. 6).

Station BATS (St. 21) in the Sargasso Sea was occupied on 13 June 2010 during our GEOTRACES-A02 section sampling cruise. The DCo concentrations analyzed by the FIAchemiluminescence method (this study, Fig. 6a and d: blue diamonds) are compared to those obtained by ICP-MS methods either in the same samples (Middag et al., 2014; Fig. 6a and d: yellow dots), or during other sampling cruises (Biller and Bruland, 2012: green triangles in Fig. 6a and d; Middag et al., 2014: red squares in Fig. 6a and d). All samples were 


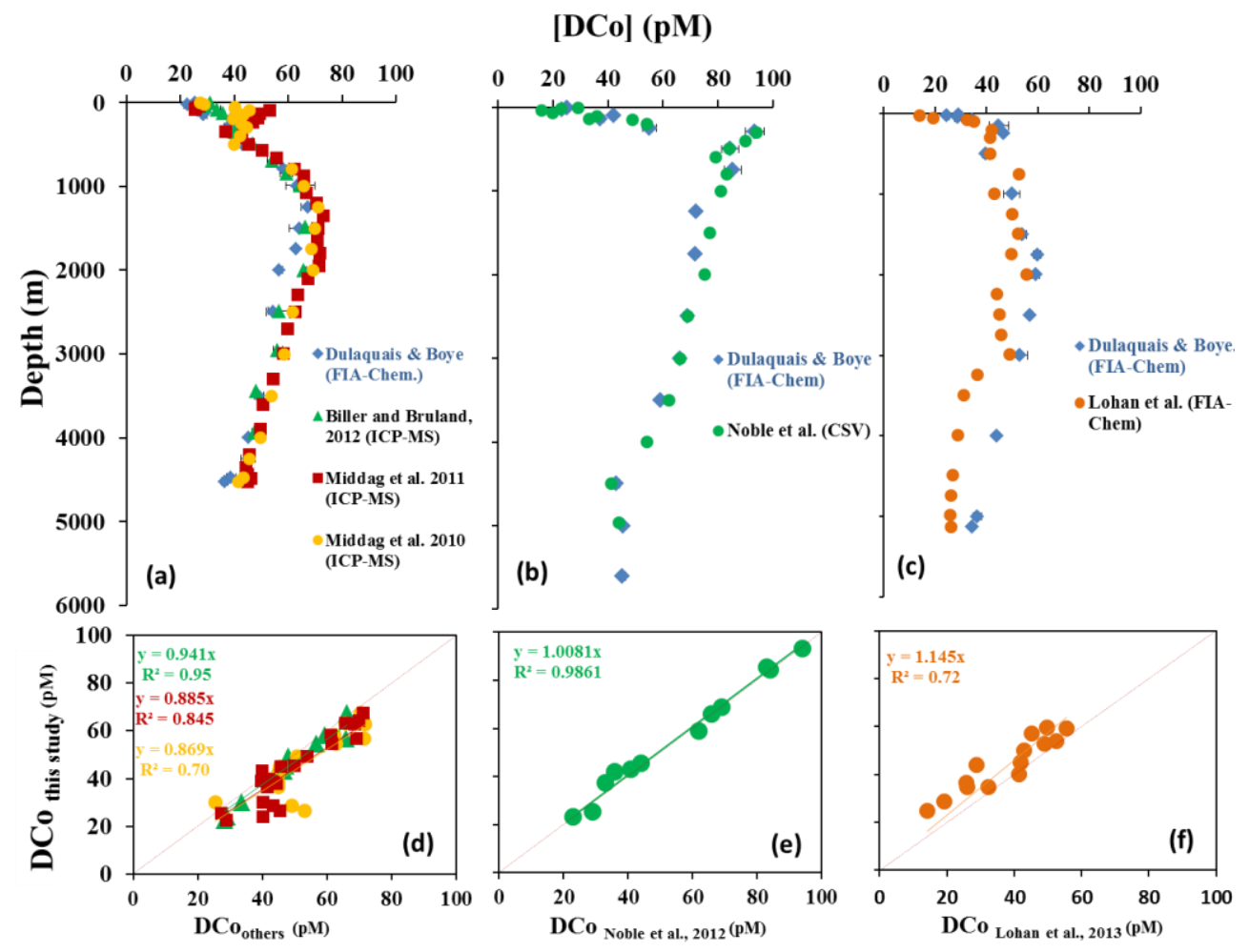

Fig. 6. Intercomparison of $D C$ data sets at the crossover station BATS (a, d) between this study (blue diamonds) and ICP-MS method by Biller and Bruland (2008) (green triangles) and by R. Middag et al. (personal communication, 2014) (yellow dots = samples from the 2010 Dutch GEOTRACES-A02 cruise; red squares = samples from the 2011 American GEOTRACES-A03 cruise); at the crossover station located at $9^{\circ} \mathrm{S}(\mathbf{b}, \mathbf{e})$ between this study (blue diamonds) and the CSV method by Noble et al. (2012) (green dots); and at the crossover station at $40^{\circ} \mathrm{S}$ (c, f) between this study (blue diamonds) with FIA-chemiluminescence method by M. C. Lohan et al. (personal communication, 2014) (orange dots $=$ samples from the 2010 English GEOTRACES-A10 cruise).

analyzed after UV treatment. In the deep waters, no significant differences were observed between the different data sets, even when samples were taken in different years. On the contrary, differences were observed in surface waters (25$200 \mathrm{~m}$ ), with systematic higher $D C$ co values using the ICPMS compared to the FIA-chemiluminescence method. It is possible that seasonal variability, especially of the Co dust deposition - which widely varies in this area (Shelley et al., 2012), would cause those variations of $D C$ Co levels recorded in surface waters (Biller and Bruland, 2012; Middag et al., 2014; Fig. 6a and d: green triangles and red squares, respectively). However, further investigations are needed because differences are also observed in the same set of samples (this study; Middag et al., 2014: yellow dots in Fig. 6a and d), yielding an offset of 6-20 pM DCo in the top- $100 \mathrm{~m}$ between the ICP-MS method and FIA-chemiluminescence analyses.

At $9^{\circ} \mathrm{S}$, the $D C$ co concentrations analyzed by FIAchemiluminescence in the samples collected during the GEOTRACES-A02 section sampling cruise (23 March 2011, St. 15 b, this study) were compared with data analyzed by cathodic stripping voltammetry after UV-treatment, but in nonacidified samples (Noble et al., 2012). Despite the fact that the two stations are not exactly at the same location and that they were sampled in different years, the hydrography and the nutrient distributions were similar (data not shown), allowing the comparison of the DCo data sets. The comparison showed an excellent correlation $\left(R^{2}>0.98\right.$; Fig. 6e), suggesting that both analytical methods were in good agreement. Less temporal variability in this area due to lesser dust inputs or coastal influences potentially allowed for the good agreement when comparing the two methods at this station.

At $40^{\circ} \mathrm{S}$, the two $D C$ data sets sampled during the GEOTRACES-A02 section cruise (10 March 2011, St. 6b, this study) and the GEOTRACES-A10 section cruise (January 2012; Lohan et al., 2014) were obtained using similar FIA-chemiluminescence methods after UV-digestion of the acidified sample. This method showed an overall good agreement between the two data sets in the upper $3000 \mathrm{~m}$ (Fig. 6c and $\mathrm{f}$ ), and an offset of $8-15 \mathrm{pM}$ in the deepest waters below $3000 \mathrm{~m}$ (Fig. 6c). The analytical methods and sample treatments were similar. However, this station was located on the Malvinas-Brazil confluence. Its position and intensity widely vary with season and with the incursion of subantarctic waters, notably of the Antarctic Intermediate Waters and Circumpolar Deep Waters. The seasonal variations can explain the differences of $D C o$ observed at intermediate and 
deeper depths between the two data sets. In the deepest waters, the difference observed in the nepheloild layer can be due to differences in the resuspension/dissolution of benthic sediments. Further investigation is needed to determine the sources of these differences.

\subsection{Large-scale transportation of dissolved cobalt in the western Atlantic}

The behavior of $D C$ in the deep ocean is still poorly understood due to the lack of observations in the full water column, notably in the western Atlantic Ocean, as well as in the Indian and the central Pacific oceans. The few studies that report $D C$ co concentrations in the deep ocean suggested a decrease of $D C$ levels in the deep waters from the Atlantic Ocean $(80.8 \mathrm{pM})$, to the Southern Ocean $(39.7 \mathrm{pM})$, and to the Pacific (28.8 pM) (Bown et al., 2011; Aparicio-Gonzalez et al., 2012). This observation has lead to the hypothesis that there is no accumulation or conservation of $D C$ o along the thermohaline circulation, and to classify $D C$, in the literature, among either the scavenged-type element like aluminium (Aparicio-Gonzalez et al., 2012) or the hybrid-type metals, those elements that have a nutrient behavior in surface waters and are strongly influenced by scavenging processes in the deep waters (Noble et al., 2008). However the scavenging of $D C$ Co invoked to interpret the deep inter-basins fractionation contrasts with $D C$ known to be stabilized in solution by strong complexation with organic ligands (conditional stability constant $\mathrm{K}_{\mathrm{CoL}}>10^{13}$ ) (Saito and Moffett, 2001; Saito et al., 2004, 2005, 2010; Bown et al., 2012a). On the other hand, other processes, such as mixing of water masses, have also been suggested to account for the decrease of $D C$ along the circulation in poor-oxygenated waters (Noble et al., 2012). We further investigated the behavior of $D C$ o along the water-masses transportation in the deep and intermediate western Atlantic, which is conceptualized in Fig. 7.

\subsubsection{Transportation in bottom waters within the core of AABW}

The Antarctic Bottom Waters spread northward with a transport of $3-5 \mathrm{~Sv}$ (where $1 \mathrm{~Sv}$ is equal to $10^{6} \mathrm{~m}^{3} \mathrm{~s}^{-1}$ ) following the topography, in an opposite direction to the overlaying NADW (Tomczak and Godfrey, 2003). The mean DCo concentration in the AABW below $4000 \mathrm{~m}$ is $41.75 \pm 5.3 \mathrm{pM}$ along the whole transect $(n=87)$, but higher $D$ Co levels are found in the older AABW flowing in the Northern Hemisphere than in the more recently formed AABW flowing in the Southern Hemisphere (mean values of $44.52 \pm 4.8 \mathrm{pM}$, $n=42$; and $39.29 \pm 4.4 \mathrm{pM}, n=45$, respectively). At the same southern latitudes, $D C$ o concentrations were similar to those reported in the core of the recently formed AABW, but in the eastern Atlantic Ocean (Bown et al., 2011; Table 2). Similar northward bottom enrichment of $D C$ in the core of AABW (see Supplement Fig. S1a), together with water mass pathway and aging, has also been observed in the eastern Atlantic sector (Bown et al., 2011). Enrichment due to mixing of the AABW with the NADW in the subarctic basin is unlikely since $D C$ display similar concentrations in the cores of these two water masses (Table 2). Bottom enrichment due to resuspension of abyssal sediments and their dissolution during AABW transportation is more likely to account for the northward increase of $D C$. Such enrichment of $D C o$ in waters following contact with basaltic sediments has recently been highlighted in a study on the Kerguelen Plateau (Bown et al., 2012b). The significant increase of $P$ Co observed close to the seafloor in the Northern Hemisphere (Fig. 5), rising up to $30 \%$ of the total cobalt concentration at $34^{\circ} \mathrm{N}$, also suggested that sediment resuspension could be significant. This is further supported by the strong signal of high dissolved aluminium concentrations observed in the bottom waters of the northern section $\left(40-50^{\circ} \mathrm{N}\right)$ (R. Midagg, NIOZ, personal communication, 2014). Additionally, the concomitant increase of $P C o$ and transmissometry near the seafloor (data not shown) strongly suggested benthic remobilization of cobalt. Finally, there was no record of high $D C o$ at the bottom of the Mid-Atlantic Ridge (Fig. 4a), suggesting that hydrothermal activity may not be acting as a significant source of $D C$ o, as previously thought (Bown et al., 2011).

\subsubsection{Transportation within the core of the NADW}

Comparison of the $D C$ co concentrations recorded in this study in the cores of the NEADW, NADW and D-AAIW with those reported in the southeastern Atlantic (Bown et al., 2011) shows an excellent agreement (Table 2). This comparison suggests that $D C$ may not be scavenged during zonal (eastward) transportation across the South Atlantic at intermediate and deep depths.

To investigate the meridional transportation of $D C o$ across the deep western Atlantic Ocean in the core of the NADW, this water mass was characterized along its route southward with respect to its mean $D C$ co concentrations at three different potential density anomaly, corresponding to its center $(\sigma 0=27.85 \pm 0.02)$, its upper-limit where the NADW interacts with intermediate waters (e.g., $\sigma 0=27.65 \pm 0.1$ ), and its lower-limit in contact with bottom waters (e.g., $\sigma 0=$ $27.89 \pm 0.015$ ) (see Supplement Fig. S1b). No significant variations were observed along these isoclines from the subarctic gyre to the equatorial area (e.g., $D C o=68.7 \pm 6 \mathrm{pM}$, $n=62$ at $\sigma 0=27.65 ; 58.8 \pm 3 \mathrm{pM}, n=19$ at $\sigma 0=27.85$; $56.9 \pm 7 \mathrm{pM}, n=21$ at $\sigma 0=27.89$ ), suggesting conservative behavior of $D C o$ in the NADW. Around the Equator, $D C$ concentration increased at two potential densities $(71.4 \pm 4.4 \mathrm{pM}, n=10$ at $\sigma 0=27.65 ; 62.6 \pm 5 \mathrm{pM}$, $n=14$ at $\sigma 0=27.85)$ and decreased in the denser waters $(D C o=51.9 \pm 8 \mathrm{pM}, n=20$ at $\sigma 0=27.89)$. There was no variation of $P C o$ in this area at $\sigma 0=27.65$ and $\sigma 0=27.85$, and there was an increase of $P$ Co at $\sigma 0=27.89$ (by $4.6 \mathrm{pM}$ ), all suggesting that remineralization of $P C o$ could not be 


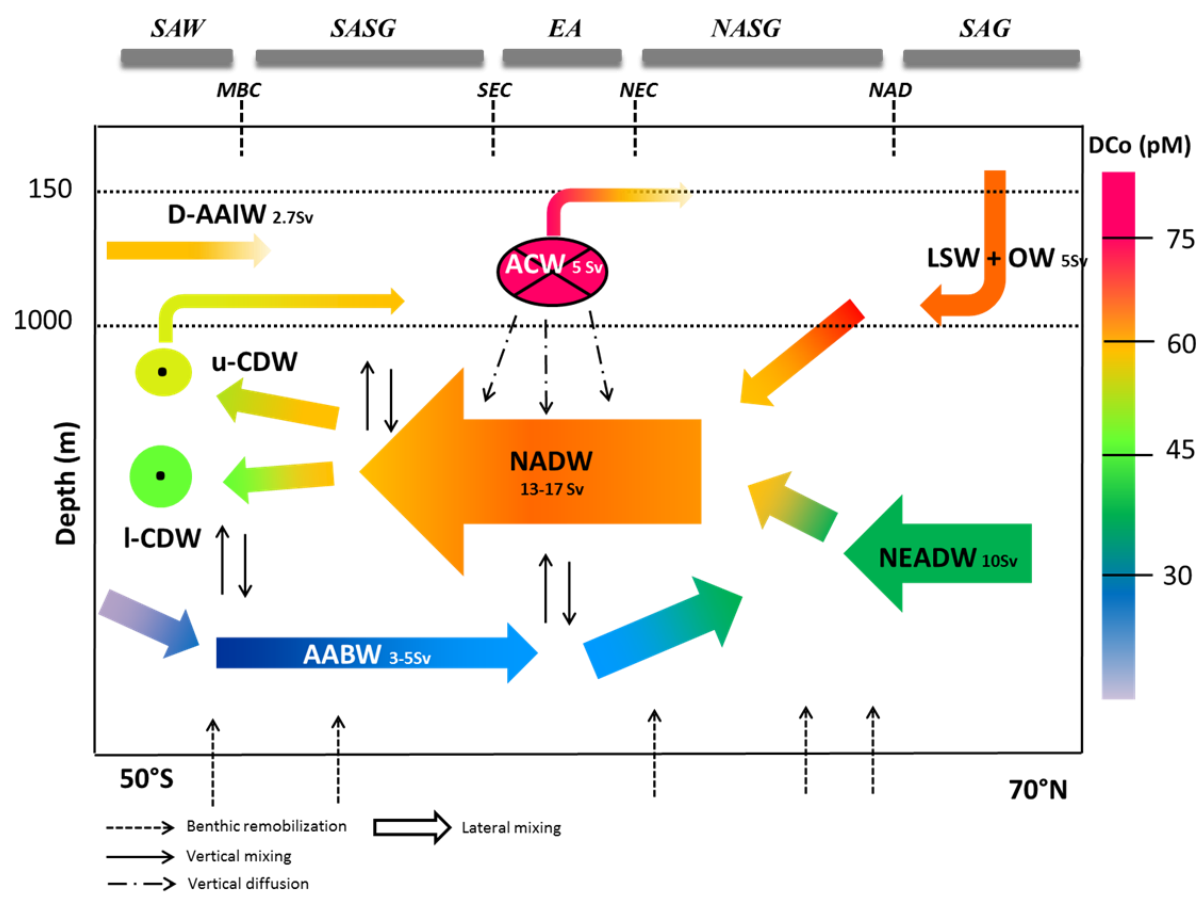

Fig. 7. Conceptual schema of the DCo transportation along the large-scale circulation in the intermediate and deep western Atlantic Ocean.

Table 2. Averaged dissolved cobalt concentration $(D C 0)$ and standard deviation (SD) obtained in the different water masses encountered along the western Atlantic GEOTRACES-A02 section: the Northeast Atlantic Deep Water (NEADW), Labrador Sea Water (LSW), North Atlantic Deep Water (NADW), Western Atlantic Central Waters (W-ACW), Northwest Antarctic Bottom Water (NW-AABW), Southwest Antarctic Bottom Water (SW-AABW), Upper Circumpolar Deep Water (UCDW) and Drake Antarctic Intermediate Water (D-AAIW).

\begin{tabular}{lllll}
\hline Water mass & $\begin{array}{l}D C o(\mathrm{pM}) \\
(\text { Others })\end{array}$ & $\begin{array}{l}\text { DCo }(\mathrm{pM}) \\
\text { (This study) }\end{array}$ & $\begin{array}{l}\text { SD }(\mathrm{pM}) \\
\text { (This study) }\end{array}$ & $\begin{array}{l}n \\
\text { (This study) }\end{array}$ \\
\hline NEADW & $53.9 \pm 3.3^{\mathrm{a}}$ & 54.3 & 2.7 & 24 \\
LSW & & 68.8 & 3.2 & 38 \\
NADW & $59.2 \pm 2.05^{\mathrm{a}}$ & 61.8 & 8.2 & 204 \\
& $70 \pm 11^{\mathrm{b}}$ & & & 41 \\
W-ACW & $79 \pm 11^{\mathrm{b}}$ & 71 & 9 & 42 \\
NW-AABW & & 44.52 & 4.8 & 45 \\
SW-AABW & $40.0 \pm 2.49^{\mathrm{a}}$ & 39.29 & 4.4 & 4 \\
& $42 \pm 12^{\mathrm{b}}$ & & & 11 \\
UCDW & $57.3 \pm 2.18^{\mathrm{a}}$ & 58.7 & 3.9 & 4.3 \\
D-AAIW & $55.8 \pm 3.68^{\mathrm{a}}$ & 53.7 & & \\
\hline
\end{tabular}

${ }^{\mathrm{a}}$ from Bown et al. (2011). ${ }^{\mathrm{b}}$ from Noble et al. (2012).

directly related to the increases in $D C o$ at those depths. Hence, the enrichment of $D C o$ in the upper NADW may be more likely due to mixing with the overlaying Western Atlantic Central Water (W-ACW), containing relatively high $D$ Co concentrations ( $>85 \mathrm{pM}$ ).

Southward, the concentrations of $D C o$ and $P C o$ in the three layers were similar to those observed in the equatorial area until $20^{\circ} \mathrm{S}(\sigma 0=27.88)$ or $30^{\circ} \mathrm{S}$ (along $\sigma 0=$ 27.65 and $\sigma 0=27.85$ ) (see Supplement Fig. S1b), again suggesting that $D C$ o behaved conservatively at those southward latitudes. However, south of $20^{\circ} \mathrm{S}$, a decrease of $D C o$ concentrations was observed along the three isoclines (see Supplement Fig. S1b). This decrease was more pronounced at the upper and lower limits than in the center of the NADW (e.g., the difference of concentrations between the North and the South Atlantic are $\triangle D \mathrm{Co}_{\sigma 0}=27.65=-11.5 \mathrm{pM}$; $\left.\Delta D \mathrm{Co}_{\sigma 0}=27.85=+1.5 \mathrm{pM} ; \Delta D \mathrm{Co}_{\sigma 0}=27.89=-10.3 \mathrm{pM}\right)$. There was no variation in the $P C o$ concentrations associated with the decreases in $D C$ at the three depths (Fig. 4b), again suggesting that scavenging of $D C$ o onto particles is not likely. Mixing and dilution of the NADW with the overlaying waters (D-AAIW in the upper limit and AABW in the lower 
layer) containing lower concentrations of $D C$ o (Table 2) are thus more likely to explain the $D C$ o decrease. Since mixing is stronger at the edges of the water masses, the center of the NADW would be less impacted by such mixing effect.

We further investigated the effect of water-masses mixing on the southward $D C$ o gradients along the NADW by calculating the $D C$ concentrations resulting from the dilution of intermediate and deep water masses (Fig. 7). In the northern section, the NADW is formed by mixing $5 \mathrm{~Sv}$ of LSW with a mean $D C$ co concentration of $68.8 \pm 3.17 \mathrm{pM}(n=38$; Table 2), with $10 \mathrm{~Sv}$ of NEADW with a mean $D C$ co concentration of $54.3 \pm 2.69 \mathrm{pM}(n=24$; Table 2) (Tomczak and Godfrey, 2003). The resulting theoretical concentration of $D C o$ of $59.13 \mathrm{pM}$ compared perfectly with the mean $D C$ o concentration observed in the NADW $(61.4 \pm 7.8, n=204$; Table 2). In the equatorial area, the mixing of $15 \mathrm{~Sv}$ of the NADW with the $4 \mathrm{~Sv}$ of the W-ACW (Schmitz, 1995) leads to a theoretical $D C$ co concentration of $66.1 \mathrm{pM}$, which is in excellent agreement with our measurements in this area $(D C o=65.3 \pm 7, n=43)$. The slight increase observed in the $D C$ concentration of the NADW in this area can thus be due to mixing between the high $D C$ concentrations of the $\mathrm{W}-\mathrm{ACW}$ and the NADW. The vertical mixing occurs through internal waves that can provide a mix of more than half of the NADW (up to $8 \mathrm{~Sv}$ ) (Webb and Suginohara, 2001). Along the southward flow of the NADW in the Southern Hemisphere, the $D C$ concentrations are higher than in the north $(D C o=63.7 \pm 7 \mathrm{pM}, n=23)$ until $30^{\circ} \mathrm{S}$, beyond which a strong decrease is observed $(D C o=54.6 \pm 7 \mathrm{pM}, n=45)$. Here, the penetration of the $2.7 \mathrm{~Sv}$ of D-AAIW (You, 2002) in the intermediate ocean, along with the $5 \mathrm{~Sv}$ of AABW in the deep sea (Tomczak and Godfrey, 2003), leads to a theoretical $D C$ co concentration of $54 \mathrm{pM}$ in the NADW, which is in excellent agreement with the concentration we measured in the NADW for this area $(54.3 \pm 6.6 \mathrm{pM}, n=41)$. Thus, mixing with overlaying water masses seems to control the concentrations of $D C$ along the circulation pathway of the NADW from the subarctic gyre to the south-western Atlantic, rather than scavenging processes. The lack of scavenging has previously been suggested in the central Atlantic (Noble et al., 2012) and in the Ross Sea (Saito et al., 2010). Here we further support that dissolved cobalt would behave conservatively in the deep western Atlantic Ocean along the thermohaline circulation. In turn, the apparent scavenged profile observed in the southern part of the section (SAW) resulted from the incursion of $D C$ Co-depleted waters at the bottom of the ocean $(\mathrm{AABW})$ and D-AAIW in intermediate waters.

\subsubsection{Temporal variation in the Subarctic gyre}

Resampling of the subarctic gyre after 2 years showed that the $D$ Co concentration increased by $20.5 \pm 5 \mathrm{pM}$ in the NEADW below $3000 \mathrm{~m}$ when comparing station $5 \mathrm{c}$ of leg 4 (2012) with the stations 8 and 11 of leg 1 (2010) at about $51^{\circ} \mathrm{N}$ (Fig. 4a). Integrated on the thickness of the
NEADW $(1250 \mathrm{~m})$, this increase corresponded to about $25.6 \pm 6.3 \mu \mathrm{mol} \mathrm{m}{ }^{-2}$. Associated with these relatively high $D C o$ concentrations, relatively high $P C o$ concentrations were also observed below $3000 \mathrm{~m}$ depth $(P C o>5 \mathrm{pM}$; Figs. $4 \mathrm{~b}$ and $5 \mathrm{~d}$ ). The transit time of the NEADW to the latitude where the increase of $D C$ co was detected is estimated to be around 2 years (Fine et al., 2001). Two possible hypotheses could be invoked to explain this anomaly observed at this location: (i) intensive sediments input in the NEADW through resuspension and dissolution, and/or diffusive processes during its circulation above the seafloor; and (ii) strong external input of cobalt to the Arctic surface waters transferred to the deep ocean by the formation of the NADW and its transportation through the deep large scale circulation.

Considering an input of $D C o$ from dissolution of basalt or granite rocks of $0.054 \pm 0.014$ to $2.00 \pm 0.22 \times$ $10^{-11} \mathrm{~mol} \mathrm{~m}^{-2} \mathrm{~d}^{-1}$ (Hausrath et al., 2009) and assuming this input would be continuous during the transit of the NEADW, the maximum cumulative input after two years of transit would be $14.6 \mathrm{nmol} \mathrm{m}^{-2}$, which is three orders of magnitude lower than the excess observed. On the other hand, when considering a diffusive flux of Co from basalt of $31.1 \mathrm{nmol} \mathrm{m}^{-2} \mathrm{~d}^{-1}$ estimated on the eastern Kerguelen Plateau (Bown et al., 2012a) and assuming a cumulative effect along the transportation of the water masses, the input would be $22.7 \mu \mathrm{mol} \mathrm{m}{ }^{-2}$, in the range of the excess in $D C o$ observed at station $5 \mathrm{c}$. However, the relatively pooroxygenated waters $\left(\mathrm{O}_{2}<200 \mu \mathrm{M}\right)$ flowing along the Kerguelen eastern slope coupled to a relative high slope current $\left(0.08 \mathrm{~cm} \mathrm{~s}^{-1}\right)$ could have enhanced sediment resuspension (Bown et al., 2012b) and makes the comparison with our rather well ventilated bottom waters $\left(\mathrm{O}_{2}>270 \mu \mathrm{M}\right)$ difficult. Furthermore, if sediment resuspension and dissolution would have caused the $D C$ anomaly, an increase in $D C$ o along the pathway of the NEADW would be expected; however, this was not observed (Fig. 4a). Therefore, it is unlikely that the benthic input of $D C$ co would cause the enhanced $D C$ concentrations that we observed in the core of the NEADW in 2012.

In April-May 2010 the Icelandic volcano Eyjafjallajökull erupted in the Arctic. The NEADW that forms in the Arctic transited for 2 years to reach the latitude where the excess of $D C o$ was observed two years after the eruption in 2012 (Fine et al., 2002). It is thus conceivable that the $D C$ e enrichment could be related to the input of these volcanic ashes and its advection by the NEADW. Volcanic ash emissions and subsequent deposition to the surface ocean have been reported to be a source of Co to the ocean (Frogner et al., 2001). Most of the ash deposition occurred close to the vent, with $98 \%$ of the tephra being transported less than $600-700 \mathrm{~km}$ from the source, and then decreasing exponentially (Gudmundsson et al., 2012). Using an ash deposition model and the mean bulk density determined by Gudmundsson et al. (2012), we estimated an ash input of $1.68 \pm 0.7 \times 10^{14} \mathrm{~g}$ of tephra in the first 
$9 \times 10^{4} \mathrm{~km}^{2}$ around Iceland, where the NEADW is formed. Using this input and a cumulative release of $8.76 \mathrm{nmol}$ of $D C o$ per gram of similar Iceland tephra (calculated after $1.5 \mathrm{~h}$ of release from Frogner, 2001), the input of $D C$ o is thus estimated at around $16.3 \pm 6.3 \mu \mathrm{mol} \mathrm{m}{ }^{-2} D C o$ in this area. Reported to the top $100 \mathrm{~m}$, it represents an input of $D C$ o of $163 \pm 63 \mathrm{pM}$, which is at least 1.5 and up to 2.5 times the concentration observed in upper $100 \mathrm{~m}$ at similar latitudes in the western subarctic gyre $\left(D \mathrm{Co}_{f} 100 \mathrm{~m}=67.2 \pm 2 \mathrm{pM}\right)$, and much higher than the excess of $D C$ o observed southward two years later $(20.5 \pm 5 \mathrm{pmol})$. Similarly, it has been shown that the 2010 Icelandic eruption had significantly enhanced iron concentrations in surface waters of the Arctic Sea, locally increasing by a factor 2.5 the iron concentration in solution even 6 days after the ash deposition (Achterberg et al., 2013). Furthermore, the mean input of $D C$ o we estimated from the volcanic ashes $\left(16.3 \pm 6.3 \mu \mathrm{mol} \mathrm{m}^{-2}\right)$ was in the same order of magnitude than the excess of $D C$ we measured two years later $\left(25.6 \pm 6.3 \mu \mathrm{mol} \mathrm{m}^{-2}\right)$. These observations strongly suggested that the volcanic eruption was a source of $D C$ o that has been advected in the core of the NADW. Because of the quick release of Co from the ash (Frogner et al., 2001), and probably because of the short residence time of these particles in the surface waters, it is possible that most of the input of $D C$ o occurred under the ash plum. Its advection by the NADW then enhanced the concentration of $D C$ o far away from the eruption, similarly to the advection of $D C$ from continental margins (Bown et al., 2011).

\subsubsection{The incursion of the Atlantic Central Waters}

The highest concentrations of $D C$ o observed at intermediate depths in the equatorial area of the section were found in the core of the Atlantic Central Waters (ACW) that originate from the eastern Atlantic (Poole and Tomczak, 1999), and those $D C o$ maxima correlated with the $\mathrm{O}_{2}$ minimum (Figs. 2c, 4a and 5c). Actually, the incursion of the ACW constituted the major reservoir of $D C o$ in the western Atlantic between the equatorial domain and the Caribbean basin (Fig. 4a). At these latitudes but in the eastern Atlantic, the $\mathrm{O}_{2}$ depletion (Tomczak and Godfrey, 2003) and the DCo concentrations ( $>150 \mathrm{pM}$; Noble et al., 2012) are even higher in the ACW compared to the western Atlantic, suggesting zonal westward transportation and decrease of $D C$ o across the central Atlantic ocean. Reductive dissolution in the pooroxygenated waters, resuspension of particulate matter in the sediments along the shelves of the eastern Atlantic, and remineralization processes were suspected to cause the $D C$ onrichment in the ACW observed in the eastern Atlantic (Noble et al., 2012). A decrease in DCo concentrations was also observed along the transit of the ACW in the eastern basin, where scavenging could not be discerned from water masses mixing (Noble et al., 2012). Once reaching our meridian section, the concentration of $D C$ continued to decrease northward in the flow of the ACW (from $93 \pm 1.3 \mathrm{pM}$ at $290 \mathrm{~m}$, St. $15 \mathrm{~b}$ to $73 \pm 0.6 \mathrm{pM}$ at $150 \mathrm{~m}$, St. 36). Accompanying these decreases, there was no significant enrichment in $P$ Co (Figs. $4 \mathrm{~b}$ and 5f), suggesting that scavenging was negligible compared to mixing and vertical diffusion. As discussed above, mixing processes with the NADW can contribute to the decrease in the $D C$ concentrations along the westward transportation of the ACW. Furthermore, using the mean decrease of $15 \mathrm{nmol} \mathrm{m}^{-3}$ of $D C$ concentrations integrated into the W-ACW from St. $15 \mathrm{~b}\left(9^{\circ} \mathrm{S} 28^{\circ} \mathrm{W}\right)$ to St. $36\left(8^{\circ} \mathrm{N} 49^{\circ} \mathrm{W}\right)$ and considering the $4 \mathrm{~Sv}$ introduced by the ACW in this area (Schmitz, 1995), we estimated a decrease rate of $D C$ o of about $5.2 \pm 0.5 \times 10^{3} \mathrm{~mol} \mathrm{~d}^{-1}$ due to the spread of the ACW northward. Reported to the surface of $2 \times 10^{6} \mathrm{~km}^{2}$ occupied by the ACW between $9^{\circ} \mathrm{S}$ and $8^{\circ} \mathrm{N}$ in the western Atlantic, this decrease rate corresponded to $2.6 \pm 0.25 \mathrm{nmol} \mathrm{m}^{-2} \mathrm{~d}^{-1}$. This zonal decrease rate compared well with the one we estimated between $10^{\circ} \mathrm{E}$ and $30^{\circ} \mathrm{W}$ using published $D C$ values for the eastern area (Noble et al., 2012). Indeed, we estimated a decrease in DCo concentrations of $56 \pm 14.8 \mathrm{nmol} \mathrm{m}^{-3}$ across the central Atlantic Ocean $\left(10 \times 10^{6} \mathrm{~km}^{2}\right)$, which corresponded to a decrease rate of $1.93 \pm 0.5 \mathrm{nmol} \mathrm{m}^{-2} \mathrm{~d}^{-1}$ when considering the ACW flow rate. In addition to dilution of the ACW, we suggest hereafter that the decreases of $D C$ can also be partially caused by vertical diffusion and advection of $D C$ o to the surface waters, especially close to the equatorial currents where frontal systems and high turbulence were observed.

\subsection{Remineralization and decoupling of the cobalt and phosphate relationship in the intermediate western Atlantic}

\subsubsection{Remineralization of cobalt in the Atlantic Central Waters}

The highest $D C$ co concentrations recorded along the section were observed in the ACW (Fig. 4a marked by the lowest concentrations of $\mathrm{O}_{2}$ (Fig. 2c)). Hence, we estimated the portion of $D C$ resulting from cumulative remineralization in the ACW by using the apparent oxygen utilization (AOU). The AOU represents the integrated oxygen consumption by heterotrophic bacteria in the breakdown of organic matter and it is computed as the difference between the oxygen saturation concentration, which depends on thermohaline properties (Weiss, 1970), and the observed oxygen concentration. The significant correlation between AOU and $D C o$ recorded in these waters (Fig. 8) strongly suggests that remineralization was driving the internal cycle of cobalt in these intermediate waters. Other studies have also reported relatively high $D C o$ concentrations in low-oxygenated waters (Saito et al., 2004; Pohl et al., 2011; Noble et al., 2012). This relationship is used to estimate the concentration of $D C o$ due to the cumulative remineralization in the ACW $\left([D C o]_{\text {remineralization }}\right.$, Eq. 1), and its proportion compared 


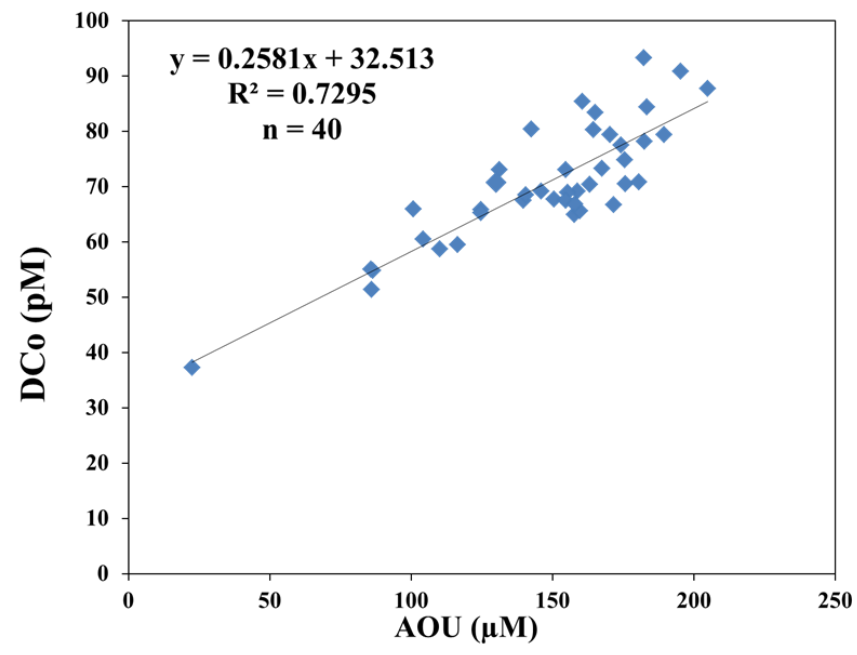

Fig. 8. Relationship among the concentrations of dissolved cobalt $(D C o)$ and the apparent oxygen utilization (AOU) in the intermediate waters of the equatorial area $(150-750 \mathrm{~m})$.

to the recorded concentration of $D C o\left(\% D C o_{\text {remineralized }}\right.$, Eq. 2), as follows:

$$
\begin{aligned}
{[D C o]_{\text {remineralization }} } & =\left(R_{\mathrm{Co}: \mathrm{P}} \times R_{\mathrm{P}: \mathrm{O} 2} \times \mathrm{AOU}\right) \\
\% D C \mathrm{Co}_{\text {remineralized }} & =100 \times[D C \mathrm{Co}]_{\text {remineralization }}
\end{aligned}
$$$$
/[D C o]_{\text {observed }}
$$

where $R_{\mathrm{Co}}: \mathrm{P}$ is the stoichiometric Co: $\mathrm{P}$ ratio recorded in the surface waters of the equatorial area (with an average value of $27 \times 10^{-6} \mathrm{M} \mathrm{M}^{-1}$; Dulaquais et al., 2014), and $R_{\mathrm{P}: \mathrm{O} 2}$ is the stoichiometric ratio between phosphate production and oxygen consumption (e.g., $R_{\mathrm{P}: \mathrm{O} 2}=1 / 170 \mathrm{M} \mathrm{M}^{-1}$; Matear and Hirst, 2003; Oschlies et al., 2008; Krishna-Murty et al., 2009).

The concentration of $D C$ due to remineralization was thus estimated at about $23 \pm 5 \mathrm{pM}$ in the western ACW between 150 and $800 \mathrm{~m}$, representing $32 \%$ of the $D C o$ measured $\left(D \mathrm{Co}_{\int} 150-800 \mathrm{~m}=71 \pm 9 \mathrm{pM}\right)$. In its layer fed by the central South Equatorial Current (CSEC, 400-800 m), the cumulative remineralized $D C$ could be even higher, representing up to $37 \%$ of $D C$ (Table 3). If this remineralized $D C$ o was only supplied by the transportation through the CSEC from the eastern basin, this proportion should be greater in the eastern central Atlantic where dilution with NADW does not affect this water mass yet. But we estimated a similar proportion in the eastern Atlantic $\left(\% D \mathrm{Co}_{\text {remineralized }}=38 \pm 5 \%\right)$ by using the $D C$ data set of Noble et al. (2012). This result suggested that the DCo provided by remineralization in the west equatorial Atlantic is likely a combination of a westward transportation of the $D C o$ remineralized in the eastern Atlantic basin, the cumulative remineralization along the transportation of ACW in these $\mathrm{O}_{2}$ depleted waters, and the mixing between NADW and $\mathrm{ACW}$ across the equatorial Atlantic and in the western basin.

\subsubsection{Decoupling of the relationship between cobalt and phosphate}

Several studies have shown that the biological utilization of $D C o$ can be proportional to that of phosphate (P) in the surface waters of oligotrophic provinces (Saito et al., 2004, 2010; Jakuba et al., 2008; Noble et al., 2008; Bown et al., 2011). However, the lower apparent remineralization of $D C$ o compared to $\mathrm{P}$ in intermediate and deep waters described by Bown et al. (2011) can suggest a decoupling between DCo and $\mathrm{P}$ in deeper waters. In our study, the absence of a significant correlation between $D C$ and $\mathrm{P}$ in intermediate and deep waters along the section $\left(R^{2}<0.1, n=446\right)$ further supported a decoupling between $D C o$ and $\mathrm{P}$ in deep waters. Furthermore, the overall lower $D C o: \mathrm{P}$ ratios observed in deep waters compared to the surface (data not shown) and the increase with depth of the Co: $\mathrm{P}$ ratio in the particles (Sherrell and Boyle, 1992; Table 3) both suggested that the decoupling can be either due to the preferential remineralization of $\mathrm{P}$ relative to $\mathrm{Co}$, or to the preferential scavenging of $D C$. However, our measurements shown that $P$ Co concentrations were not increasing with depth but instead they were rather decreasing (Table 3 ), strongly suggesting that scavenging of $D C o$ could be negligible. Hence, we further investigated the impact of the remineralization on the decoupling between $D C o$ and $\mathrm{P}$ in the equatorial area where the OMZ was located and where ACW dispatched the highest $D C$ concentrations recorded along the section. The proportion of $\mathrm{P}$ due to the cumulative remineralization $\left(\% \mathrm{P}_{\text {remineralized }}\right)$ was thus estimated according to

$\% P_{\text {remineralized }}=100 \times\left(R_{\mathrm{P}: \mathrm{O} 2} \times \mathrm{AOU}\right) /[P]_{\text {observed }}$.

In this area, the proportion of $\mathrm{P}$ and Co produced by the cumulative remineralization was estimated in the surface layer mainly impacted by the geostrophic currents $(0-150 \mathrm{~m})$, the upper layer of the ACW which was influenced by the North Brazil Undercurrent, the equatorial and central branches of the South Equatorial Current, all forming the North Brazil Current at these depths (150-400 m), and the lower layer of the ACW mostly fed by the CSEC (400-800 m). It shown that the proportion of $\mathrm{P}$ provided by cumulative remineralization increased by a factor 7.4 between the surface layer and upper-ACW, whereas this increase was much lower for $D C$ o (factor 1.5) (Table 3). This result suggested that the remineralization of $\mathrm{P}$ and $D C$ co was not proportional in intermediate waters, and further supported the hypothesis that the preferential remineralization of $\mathrm{P}$ relative to $D C$ can largely cause the decoupling in deeper waters. Furthermore, the strongest remineralization of $D C$ o that occurred deeper than that of $\mathrm{P}$ in the core of the lower-ACW (Table 3) may also lead to the decoupling between the deep cycles of $D C o$ and P. Determination of the particles composition in $\mathrm{Co}$ and $\mathrm{P}$ would further help in understanding the processes involved in this decoupling. 
Table 3. Mean dissolved cobalt concentration ( $D C \mathrm{C} ; \mathrm{pM})$, mean apparent particulate cobalt concentration $(P C o ; \mathrm{pM})$, and percentages of dissolved cobalt and phosphate produced by cumulative remineralization (respectively $D C \mathrm{Com}_{\text {rem }}$ and $P_{\text {rem }} ; \%$ ) calculated in the surface layer $(0-150 \mathrm{~m})$, the upper layer of Atlantic Central Waters $(150-400 \mathrm{~m})$ and the lower layer of Atlantic Central Waters (400-800 m) between $10^{\circ} \mathrm{S}$ and $10^{\circ} \mathrm{N}$ (see text for definitions and calculation). The particulate ratios of $\mathrm{Co}: \mathrm{P}\left((\mathrm{Co} / \mathrm{P})_{\text {in particles }} ; \mu \mathrm{M} \mathrm{M}^{-1}\right)$ recorded in the western Atlantic (Sherrell and Boyle, 1992) are also indicated for comparison. Errors are given as standard deviation from averaged values.

\begin{tabular}{llllll}
\hline Depth $(\mathrm{m})$ & $D \mathrm{Co}_{0}(\mathrm{pM})$ & $P \mathrm{Co}_{0}(\mathrm{pM})$ & $D \mathrm{Co}_{\text {Rem }}(\%)$ & $P_{\text {Rem }}(\%)$ & $\begin{array}{l}(\mathrm{Co} / \mathrm{P})_{\text {in particles }} \\
\left(\mu \mathrm{M} \mathrm{M}^{-1}\right)\end{array}$ \\
\hline $0-150$ & $\begin{array}{l}32 \pm 12 \\
(n=37)\end{array}$ & $\begin{array}{l}4 \pm 3 \\
(n=13)\end{array}$ & $22 \pm 5$ & $7 \pm 1$ & $403 \pm 128$ \\
$150-400$ & $\begin{array}{l}70 \pm 11 \\
(n=28)\end{array}$ & $\begin{array}{l}2 \pm 2 \\
(n=9)\end{array}$ & $32 \pm 6$ & $51 \pm 6$ & $2718 \pm 1180$ \\
$400-800$ & $\begin{array}{l}72 \pm 6 \\
(n=19)\end{array}$ & $\begin{array}{l}2 \pm 1 \\
(n=8)\end{array}$ & $37 \pm 3$ & $40 \pm 2$ & $5420 \pm 2440$ \\
\hline
\end{tabular}

\subsection{Physical processes impacting the distribution of dissolved cobalt in surface waters}

\subsubsection{Lateral advection in surface waters}

The lateral advection from continental margin is thought to be a source of $D C$ in the open surface ocean (Bown et al., 2011, 2012b; Noble et al., 2012), but this source is still largely uncharacterized. Therefore, we estimated the lateral advective $D C$ co supply in the surface waters of the section $\left(F D \mathrm{Co}_{\text {adv }} ;\right.$ Eq. 4$)$ by calculating the local geostrophic velocities $(u, v$; referenced 1000 dbars) based on sea level anomalies (SLA, www.aviso.oceanobs.com), and using the lateral $D C o$ gradients $(x, y)$ integrated in the upper $150 \mathrm{~m}(z)$ between two nearby stations ( $a, b$; Eq. 5), using the following equations:

$$
\begin{aligned}
F D \operatorname{Co}_{\mathrm{adv}}(\mathrm{a})= & \operatorname{Grad} D \mathrm{Co}_{(x, y)} \times \text { velocity }_{\mathrm{a}} \times z \\
\operatorname{Grad} D \operatorname{Co}_{(x, y)}= & {\left[\left(D \operatorname{Co}_{\mathrm{b}} \int 150 \mathrm{~m}\right)\right.} \\
& \left.-\left(D \mathrm{Co}_{\mathrm{a}} \int 150 \mathrm{~m}\right)\right] / d_{\mathrm{a} \rightarrow \mathrm{b}},
\end{aligned}
$$

where $D \mathrm{Co}_{i} \int 150 \mathrm{~m}$ is the mean $D C$ concentration integrated over the upper $150 \mathrm{~m}$ at station (i); velocity ${ }_{i}$ is the lateral geostrophic velocity at station (i) integrated over the upper $150 \mathrm{~m} ; z$ is equal to $150 \mathrm{~m}$; and $d_{a \rightarrow b}$ is the distance between stations (a) and (b). A positive velocity is associated with a positive SLA and represents an advection from the considered station, and inversely for a negative velocity.

The dynamic structures with high lateral geostrophic velocities were generally observed in the frontal zones along the section (Table 4) and were associated with strong local currents (up to $20 \mathrm{~cm} \mathrm{~s}^{-1}$, as observed at $5^{\circ} \mathrm{N}$ ), whereas relatively low velocities were estimated in the center of each oceanic domain $\left(<2 \mathrm{~cm} \mathrm{~s}^{-1}\right)$. However, isolated events such as eddies were also identified in the center of the NASG (Table 4). The estimations of the lateral advective fluxes of $D C$ in surface waters showed variations of more than two orders of magnitude between the different areas (Table 4). For instance, in the center of the domains like at the station BATS, the geostrophic velocities and lateral $D C o$ gradients were smooth, resulting in negligible lateral fluxes of $D C o\left(-1 \mathrm{nmol} \mathrm{m}^{-2} \mathrm{~d}^{-1}<F D \mathrm{Co}_{\mathrm{adv}}<1 \mathrm{nmol} \mathrm{m}^{-2} \mathrm{~d}^{-1}\right)$. On the contrary, in the frontal zones where turbulence and significant lateral $D C$ o gradients can be observed, the lateral advection fluxes of $D C$ o were relatively high in surface waters (from $-61 \mathrm{nmol} \mathrm{m}^{-2} \mathrm{~d}^{-1}$ to $55 \mathrm{nmol} \mathrm{m}^{-2} \mathrm{~d}^{-1}$, Table 4).

The $D C$ co fluxes from lateral advection in surface waters can be important at a given station, but at the scale of a domain the impact was relatively limited, especially in the SASG. Indeed, at this scale the sum of the fluxes was low $\left(-3 \mathrm{nmol} \mathrm{m}^{-2} \mathrm{~d}^{-1}<F D C o<3 \mathrm{nmol} \mathrm{m}^{-2} \mathrm{~d}^{-1}\right)$. Nevertheless, the lateral advection within mesoscale structures, such as eddies, can be particularly important for the transportation of $D C$ co to interior basins, as it has been previously observed in the oligotrophic domain of the southeastern Atlantic where inputs of $D C$ fo from continental margins were carried by Agulhas rings (Bown et al., 2011). Moreover, eddies can allow exchanges of $D C o$ between the different domains along the section, especially between the central Atlantic and the NASG through the equatorial current system, and between the SASG and the ECC through the MBC. Local turbulence associated with eddies can also induce local vertical advection (such as upwelling in the core of cyclonic eddies) as well as diffusion of $D C$ o from the intermediate waters. It has been shown that such physical processes can affect the vertical distribution of $D C$ in surface waters (Noble et al., 2008; Shelley et al., 2012). All these direct and indirect effects make these dynamical structures sources or sinks of $D C$ o to the surface layer.

\subsubsection{The vertical diffusion}

The vertical diffusion has been described as an important source of iron $(\mathrm{Fe})$ and other nutrients to the euphotic layer, sustaining phytoplankton development in Fe-depleted areas (Law et al., 2003; Croot et al., 2005; Blain et al., 2008). In the equatorial Atlantic this internal source of Fe may be even greater than the input of Fe from Saharan dust deposition 
Table 4. Lateral gradient of dissolved cobalt $\left(\operatorname{Grad} D C \operatorname{Co}_{\int} 150 \mathrm{~m} ; 10^{-5} \mathrm{nmol} \mathrm{m}^{-3} \mathrm{~m}^{-1}\right)$, and lateral advective fluxes of dissolved cobalt $\left(F D \mathrm{Co}_{\mathrm{adv}} ; \mathrm{nmol} \mathrm{m}{ }^{-2} \mathrm{~d}^{-1}\right)$ generated by local geostrophic lateral advection $\left(F w_{\mathrm{Geo}} ; \mathrm{cm} \mathrm{s}^{-1}\right)$ are given in the upper $150 \mathrm{~m}$ for several sampling stations corresponding to key dynamical structures or domains.

\begin{tabular}{llrrr}
\hline Location & Structure & ${\text { Grad } D \mathrm{Co}_{f 150 \mathrm{~m}}}$ & $F w_{\text {Geo }}$ & $F D C \mathrm{Co}_{\text {adv }}$ \\
\hline St. $5\left(37^{\circ} \mathrm{W}, 60^{\circ} \mathrm{N}\right)$ & Center of SAG & +0.39 & -0.23 & -0.11 \\
St. $15\left(50^{\circ} \mathrm{W}, 37.5^{\circ} \mathrm{N}\right)$ & Anti-cyclonic eddy & +1.37 & -9.73 & -17.28 \\
St. 21 $(\mathrm{BATS})$ & Center of NASG & -0.39 & -0.16 & 0.08 \\
St. 25 $\left(67^{\circ} \mathrm{W}, 25^{\circ} \mathrm{N}\right)$ & Cyclonic eddy & -0.15 & +13.28 & -2.54 \\
St. $36\left(48.9^{\circ} \mathrm{W}, 7.8^{\circ} \mathrm{N}\right)$ & NEC & -3.21 & +10.03 & -41.67 \\
Btw St. 37-38 $\left(45^{\circ} \mathrm{W}, 5^{\circ} \mathrm{N}\right)$ & ECC & -2.08 & -19.99 & 54.82 \\
Btw St. $16 \mathrm{~b}-17 \mathrm{~b}\left(28.5^{\circ} \mathrm{W}, 5^{\circ} \mathrm{S}\right)$ & SEC & -0.61 & +3.92 & 3.19 \\
St. $2 \mathrm{~b}\left(32.7^{\circ} \mathrm{W}, 22.5^{\circ} \mathrm{S}\right)$ & Center SASG & +0.62 & +1.15 & +0.92 \\
St. 6b $\left(42.5^{\circ} \mathrm{W}, 40^{\circ} \mathrm{S}\right)$ & MBC & -1.58 & -7.76 & 15.85 \\
Btw St. 2b-3b $\left(48^{\circ} \mathrm{W}, 48^{\circ} \mathrm{S}\right)$ & Malvinas current & +0.02 & -7.54 & -0.23 \\
\hline
\end{tabular}

(Rijkenberg et al., 2012). However, the importance of this supply for $D C$ co still has to be determined in the ocean. In the Southern Ocean and above the Kerguelen Islands the supply of $D C$ o to surface waters by vertical diffusion has been estimated to be negligible due to the small gradient in $D C o$ concentrations between the euphotic and mesopelagic layers caused by low biological assimilation of $D C o$ in these diatom-dominated waters (Bown et al., 2011, 2012b). By contrast, strong vertical gradients in $D C$ co concentrations between the surface and the nutricline were observed along the section in the western Atlantic Ocean, especially in the equatorial area (Fig. 5), allowing us to estimate this supply.

Briefly, the diffusion depends on the vertical gradient of $D C$ co concentrations, the diffusion coefficient $\left(D_{T}\right)$ and the turbulent diffusivity coefficient $\left(K_{z}\right)$. Whereas $D_{T}$ is a physico-chemical property of the component within water (molecular property), the turbulent diffusivity coefficient is solely a property of the turbulent fluid. If the vertical gradient of concentrations $(\partial D C o / \partial z)$ is much higher than the lateral gradients $(\partial \mathrm{Co} / \partial x \approx \partial D \mathrm{Co} / \partial y)$, the lateral diffusion is considered negligible (see Tables 4 and 5). Furthermore, the values of $K_{z}$ estimated along the section (M. Rijkenberg, NIOZ, personal communication, 2013) were three to six orders of magnitude higher than $D_{T}$; hence, the molecular diffusivity was considered negligible. The highest values of $K_{z}$ were found near frontal zones (M. Rijkenberg, NIOZ, personal communication, 2013) where strong geostrophic velocities were observed. One to two orders of magnitude lower turbulent diffusivities were found in the subtropical domains, coherent with lower turbulence of the water column and lower wind stress.

The intrusion of the ACW in the southern side of the equatorial area and its northward flow along the coast of South America through the Guyana and Caribbean Currents (Poole and Tomczak, 1999) transported relatively high $D C$ within the mesopelagic layer and at the bottom of the euphotic layer $\left(100-250 \mathrm{~m}\right.$ ) between $10^{\circ} \mathrm{S}$ and $10^{\circ} \mathrm{N}$ (Fig. 4a). Due
Table 5. Vertical dissolved cobalt gradient $(\Delta D C o / \Delta z 100-300 \mathrm{~m}$; nmol m$\left.{ }^{-3} \mathrm{~m}^{-1}\right)$, mean $K_{z_{100-300 \mathrm{~m}}}\left(\mathrm{~cm}^{2} \mathrm{~s}^{-1}\right)$ and vertical dissolved cobalt fluxes from the mesopelagic layer to the euphotic layer $\left(F D C o_{\text {vertical diff. }}\right.$ nmol m${ }^{-2} \mathrm{~d}^{-1}$ ) at few stations representative of the different areas crossed along the section (see text for the details of the calculations).

\begin{tabular}{lrrr}
\hline Location & $\begin{array}{r}\Delta D \mathrm{Co} / \Delta z \\
100-300 \mathrm{~m}\end{array}$ & $K_{z}$ & $F D \mathrm{Co}_{\text {vertical diff. }}$ \\
\hline St. 15 $\left(50^{\circ} \mathrm{W} ; 37.5^{\circ} \mathrm{N}\right)$ & 0.115 & 7.03 & +6.96 \\
St. 21 (BATS) & 0.069 & 0.08 & +0.05 \\
St. 26 $\left(65.5^{\circ} \mathrm{W} ; 23.3^{\circ} \mathrm{N}\right)$ & 0.121 & 0.07 & +0.07 \\
St. 36 $\left(48.9^{\circ} \mathrm{W} ; 7.8^{\circ} \mathrm{N}\right)$ & 0.291 & 2.44 & +6.13 \\
St. 15b $\left(28^{\circ} \mathrm{W} ; 9^{\circ} \mathrm{S}\right)$ & 0.305 & 1.23 & +3.16 \\
St. 12b $\left(32.7^{\circ} \mathrm{W} ; 22.5^{\circ} \mathrm{S}\right)$ & 0.062 & 0.11 & +0.06 \\
St. 6b $\left(42.5^{\circ} \mathrm{W} ; 40^{\circ} \mathrm{S}\right)$ & 0.084 & 3.72 & +2.69 \\
\hline
\end{tabular}

to relatively high $D C$ assimilation in surface waters at these latitudes (Dulaquais et al., 2014), strong DCo vertical gradients were generated between the surface and intermediate waters (Figs. 4a and 5). For instance, the $D C$ co vertical gradient can be as high as $0.31 \mathrm{nmol} \mathrm{m}^{-3} \mathrm{~m}^{-1}$ in the equatorial area at $9^{\circ} \mathrm{S}$. By contrast, the vertical gradients are generally smooth in the subtropical domains and in the subarctic gyre $\left(<0.07 \mathrm{nmol} \mathrm{m}^{-3} \mathrm{~m}^{-1}\right)$. Combining the vertical gradients with the $K_{z}$ pattern, it is obvious that the vertical diffusion $D C$ o supply was expected to be higher in the frontal zones of the equatorial area than in the other domains. To further assess the role of the vertical diffusion on the distribution of $D C o$ in surface waters, we estimated the $D C$ o vertical diffusion flux $\left(F D \mathrm{Co}_{\text {diffusion }}\right)$ in the different domains using the following equation:

$F D \mathrm{Co}_{\text {diffusion }}=-\left(K_{z}+D_{T}\right) \times(\partial D \mathrm{Co} / \partial z)$

with $10^{3}<\left(K_{z} / D_{T}\right)<10^{6}$.

The $D C$ o supply to the euphotic layer by vertical diffusion (Table 5) varies by two orders of magnitude between the frontal zones (e.g., $7 \mathrm{nmol} \mathrm{m}^{-2} \mathrm{~d}^{-1}$ in the north subtropical 
frontal zone) and the center of the subtropical domains (e.g., $>0.07 \mathrm{nmol} \mathrm{m}^{-2} \mathrm{~d}^{-1}$ in the oligotrophic domains). In the frontal systems, the highest turbulence (Table 5) combined with a significant vertical gradient of $D C$ concentrations caused high vertical diffusion fluxes of $D C$ into the surface waters. In the equatorial area the high diffusive input of $D C o$ was mainly due to high vertical gradients of $D C o$ induced by the incursion of the eastern south ACW enriched in $D C$. This input may well sustain the growth of the cyanobacteria present in the equatorial domain towards $15^{\circ} \mathrm{N}$ (TovarSanchez et al., 2006). By contrast, this input kept relatively low in the oligotrophic domains mainly due to lower turbulent fluids. Therefore, the vertical diffusion did not appear to be the dominant flux to sustain the cyanobacteria population in the oligotrophic domains of the western Atlantic. However, in these subtropical areas, eddies that locally increase the turbulence and thus vertical advection/diffusion (Noble et al., 2008) added to external sources such as dust deposition or rivers discharge (Tovar-Sanchez et al., 2006; Dulaquais et al., 2014) may rather be invoked than isopycnal diffusion to respond to the absolute requirement of the dominant cyanobacteria for cobalt (Saito and Moffett, 2001).

\section{Conclusions}

Large-scale observation of the deep distribution of dissolved cobalt as first assessed in this work allowed to further understand the role of physical and remineralization processes in the deep cycle of cobalt. In deep waters , $D$ Co behaves conservatively along water masses transportation through the western Atlantic. Mixing and dilution of deep water masses, rather than scavenging of $D C$ onto settling particles, generate the meridional decrease of $D C$ along the southward large-scale circulation in the deep western Atlantic. This finding contrasted with previous interpretations which suggested that $D C o$ is scavenged along the thermohaline circulation explaining the deep inter-basins fractionation (Bruland and Lohan, 2003). In addition, the conservative behavior of $D C$ allowed the persistence of relatively high concentrations in the core of the LSW and low concentrations in the underlaying AABW, hence generating the apparent scavenged profile of $D C$ o observed in the deep waters of the western Atlantic. It also allowed large-scale transportation of external cobalt sources to interior basins, such as the 2010 Icelandic volcanic eruption, which was depicted by relatively high $D C$ co concentrations in the core of the NEADW at $51^{\circ} \mathrm{S}$. In addition, the $D C$ co enriched intermediate waters can act as internal inputs of $D C$ into the surface waters through dynamic processes. Eddies and dynamical structures such as equatorial surface jets could play a major role in the fertilization of surface water in $D C$ o through vertical diffusion and lateral advection. The input of $D C$ o by the vertical diffusion is particularly enhanced in the equatorial domain where the incursion of the Atlantic Central Waters at intermediate depths that transports high $D C$ co concentrations compared to the surface, generating a strong vertical $D C$ o gradient. However, these processes are still poorly constrained and may act as sinks as well; further work is required to better constrain these fluxes.

Next to physical processes, reductive processes - notably those linked to the oxygenation of the water masses - also play a major role in the deep cycle of $D C$. The ACW characterized by relatively low $\mathrm{O}_{2}$ indeed exhibited the highest $D C o$ concentrations encountered along the section, hence constituting the major reservoir of $D C$ in the western Atlantic. The relatively low oxygenation of these waters may have promoted the stabilization of $D C o$ in the westward flow of the ACW across the Atlantic Ocean, whereas physical processes did not prevent $D C$ o to decrease along the route of these waters due to mixing and dilution with other water masses containing less $D C o$ and to vertical diffusion to surface waters. In addition, the significant correlation between $D C$ concentrations and the apparent oxygen utilization found in these waters further indicated that remineralization (abiotic and biotic) was driving the internal cycle of cobalt in these intermediate waters. The remineralization of $D C o$ was not proportional to that of phosphate in these intermediate waters, unlike the biological uptake of both $D C o$ and $\mathrm{P}$ previously reported in oligotrophic surface waters (e.g., Saito et al., 2002; Noble et al., 2008; Bown et al., 2011). This decoupling leads to an enrichment of Co relative to $\mathrm{P}$ in the settling particles, mainly due to the preferential remineralization of $P$ rather than a preferential scavenging of Co. Records of truly particulate cobalt will further help in revealing the role of particles in the deep cycle of cobalt.

\section{Supplementary material related to this article is available online at http://www.biogeosciences.net/11/ 1561/2014/bg-11-1561-2014-supplement.pdf.}

Acknowledgements. We are indebted to the captains, officers and crew members of the R/V Pelagia and RRS James Cook: without their exceptional support, this large ocean section would not have been possible. We are most grateful to H. J. W. de Baar, the Coordinator of the Dutch Project, and to Loes Gerringa and Micha Rijkenberg, the Chief Scientists of the cruises. We warmly thank Jan van Ooijen, K. Bakker, E. van Weerlee, S. Ossebaar for the analyses of nutrients, as well as S. Ober, Martin Laan, Steven van Heuven, S. Asjes and L. Wuis for providing high quality CTD data. This investigation was supported by the GEOTRACES-GEOSECS revisited in the western Atlantic project coordinated by Marie Boye and funded by the French LEFE-CYBER National Program of the Institut National des Sciences de l'Univers (INSU). We also acknowledge the European COST-Action ES801 for funding a Short Term Scientific Mission to Gabriel Dulaquais to join the last cruise. The Université de Bretagne Occidentale (UBO) and the Région Bretagne are supporting the $\mathrm{PhD}$ fellowship of G. Dulaquais. This 
investigation is a contribution to the international GEOTRACES program. The two referees, Johann Bown and Abigail Noble, are warmly acknowledged for their constructive remarks, which improved the manuscript.

Edited by: G. Herndl

\section{References}

Achterberg, E. P., Mark Moore, C., Henson, S. A., Steigenberger, S., Stohl, A., Eckhardt, S., Avendano, L. C., Cassidy, M., Hembury, D., Klar, J. K., Lucas, M. I., Macey, A. I., Marsay, C. M., and Ryan-Keogh, T. J.: Natural iron fertilization by the Eyjafjallajökull volcaniceruption, Geophys. Res. Lett., 40, 921-926, 2013.

Aparicio-Gonzalez A., Duarte C. M., Tovar-Sanchez A.: Trace metals in deep ocean waters: A review, J. Mar. Systems, 100, 26-33, 2012.

Biller, D. V. and Bruland, K. W.: Analysis of Mn, Fe, Co, Ni, Cu, $\mathrm{Zn}, \mathrm{Cd}$, and $\mathrm{Pb}$ in seawater using the Nobias-chelate PA1 resin and magnetic sector inductively coupled plasma mass spectrometry (ICP-MS), Mar. Chem., 130-131, 12-20, 2012.

Blain, S., Quéguiner, B., Armand, L., Belviso, S., Bombled, B., Bopp, L., Bowie, A., Brunet, C., Brussaard, C., Carlotti F., Christaki, U., Corbière, A., Durand, I., Ebersbach, F., Fuda, J-L., Garcia, N., Gerringa, L., Griffiths, B., Guigue, C., Guillerm, C., Jacquet, S., Jeandel, C., Laan, P., Lefèvre, D., Lo Monaco, C., Malits, A., Mosseri, J., Obernosterer, I., Park, Y.-H., Picheral, M., Pondaven, P., Remenyi, T., Sandroni, V., Sarthou, G., Savoye, N., Scouarnec, L., Souhaut, M., Thuiller, D., Timmermans, K., Trull, T., Uitz, J., van Beek, P., Veldhuis, M.,Vincent, D., Viollier, E., Vong, L., and Wagener, T.: Effect of natural iron fertilization on carbon sequestration in the Southern Ocean, Nature, 446, 10701074, 2007.

Bowie, A. R. and Lohan, M. C.: Analysis of iron in seawater, in Practical Guidelines for the Analysis of Seawater, edited by: Wurl, O., chapter 12, 235-257, Taylor and Francis, Boca Raton, Fla., ISBN:978-1-4200-7306-5, 2009.

Bown, J., Boye, M., Baker, A., Duvieilbourg, E., Lacan, F., Le Moigne, F., Planchon, F., Speich, S., and Nelson, D. M.: The biogeochemical cycle of dissolved cobalt in the Atlantic and the Southern Ocean south off the coast of South Africa, Mar. Chem., 126, 193-206, doi:10.1016/j.marchem.2011.03.008, 2011.

Bown, J., Boye, M., and Nelson, D. M.: New insights on the role of organic speciation in the biogeochemical cycle of dissolved cobalt in the southeastern Atlantic and the Southern Ocean, Biogeosciences, 9, 2719-2736, doi:10.5194/bg-9-27192012, 2012a.

Bown, J., Boye, M., Laan, P., Bowie, A. R., Park, Y.-H., Jeandel, C., and Nelson, D. M.: Imprint of a dissolved cobalt basaltic source on the Kerguelen Plateau, Biogeosciences, 9, 5279-5290, doi:10.5194/bg-9-5279-2012, 2012b.

Boyd, P. W. and Ellwood, M. J.: The biogeochemical cycle of iron in the ocean, Nat. Geosci., 3, 675-682, 2010.

Bruland, K. W. and Lohan, M. C.: The control of trace metals in seawater, in: The Oceans and Marine Geochemistry, Treatise on Geochemistry, Vol. 6., edited by: Elderfield, H., Elsevier, 2003.

Cannizzaro, V., Bowie, A. R., Sax, A., Achterberg, E. P., and Worsfold, P. J.: Determination of cobalt and iron in estuarine and coastal waters using flow injection with chemiluminescence detection, The Analyst, 125, 51-57, 2000.

Croot, P. L., Laan, P., Nishioka, J., Strass, V., Cisewski, B., Boye, M., Timmermans, K. R., Bellerby, R. G., Goldson, L., Nightingale, P. L., de Baar, H. J. W.: Spatial and temporal distribution of $\mathrm{Fe}$ (II) and $\mathrm{H}_{2} \mathrm{O}_{2}$ during EisenEx, an open ocean mescoscale iron enrichment, Marine Chem., 95, 65-88, 2005.

De Baar, H. J. W., Timmermans, K. R., Laan, P., De Porto, H. H., Ober, S., Blom, J. J., Bakker, M. C., Schilling, J., Sarthou, G., Smit, M. G., and Klunder, M.: Titan: A new facility for ultraclean sampling of trace elements and isotopes in the deep oceans in the international GEOTRACES program, Mar. Chem., 111, 4$21,2008$.

Dulaquais G., Boye M., Middag R., Owens S., Puigcorbé V., Masqué P., Buesseler K., de Baar, H., and Carton, X.: How to constrain the biogeochemical cycle of cobalt in the surface West Atlantic Ocean?, Global Biogeoch. Cy., in preparation, 2014.

Ellwood, M. J.: Wintertime trace metal ( $\mathrm{Zn}, \mathrm{Cu}, \mathrm{Ni}, \mathrm{Cd}, \mathrm{Pb}$ and $\mathrm{Co})$ and nutrient distributions in the subantarctic zone between 40-52 ${ }^{\circ}$ S; 155-160 E., Mar. Chem., 112, 107-117, 2008.

Fine, R. A., Rhein, M., and Andrie, C.: Using a CFC effective age to estimate propagation and storage of climate anomalies in the deep western North Atlantic Ocean, Geophys. Res. Lett., 29, 2227-2230, 2002.

Fitzwater, S. E., Johnson, K. S., Gordon, R. M., Coale, K. H., and Smith, W. O.: Trace metal concentrations in the Ross Sea and their relationship with nutrients and phytoplankton growth, Deep-Sea Res. Pt II, 47, 3159-3179, 2000.

Frogner, P., Gislason, S. R., and Oskarsson, N.: Fertilizing potential of volcanic ash in ocean surface water, Geology, 29, 487-490, 2001.

Gislason, S. R., Hassenkam, T., Nedel, S., Bovet, N., Eiriksdottir, E. S., Alfredsson, H. A., Hem, C. P., Balogh, Z. I., Dideriksen, K., Oskarsson, N., Sigfusson, B., Larsen, G., and Stipp, S. L. S.: Characterization of Eyjafjallajokull volcanic ash particles and a protocol for rapid risk assessment, Proc. Nat. Acad. Sci., 108, 7307-7312, 2011

Gladyshev, S., Arhan, M., Sokov, A., and Speich, S.: A hydrographic section from South Africa to the southern limit of the Antarctic Circumpolar Current at the Greenwich meridian, DeepSea Res. Pt. I, 55, 1284-1303, 2008.

Grasshoff, K., Ehrhardt, M., and Kremling, K.: Methods of seawater analysis., Verlag Chemie GmbH, Weinheim, 419 pp., 1983.

Gudmundsson, M. T., Thordarson, T., Höskuldsson, Á., Larsen, G., Björnsson, H., Prata, F. J., Oddsson, B., Magnússon, E., Högnadóttir, T., Petersen, G. N., Hayward, C. L., Stevenson, J. A., and Jónsdóttir, I.: Ash generation and distribution from the AprilMay 2010 eruption of Eyjafjallajokull, Iceland, Nature Scientifc Reports, 2, 572, doi:10.1038/srep00572, 2012.

Hausrath, E. M., Neaman, A., and Brantley, S. L.: Elemental release rates from dissolving basalt and granite with and without organic ligands, Am. J. Sci., 309, 633-660, doi:10.2475/08.2009.01, 2009.

Jakuba, R. W., Moffett, J. W., and Dyhrman, S. T.: Evidence for the linked biogeochemical cycling of zinc, cobalt, and phosphorus in the western North Atlantic Ocean, Global Biogeochem. Cy., 22, GB4012, doi:10.1029/2007GB003119, 2008.

Knauer, G. A., Martin, J. H., and Gordon, R. M.: Cobalt in Northeast Pacific Waters, Nature, 297, 49-51, 1982. 
Krishnamurthy, A., Moore, J., Mahowald, N., Luo, C., Doney, S., Lindsay, K., and Zender, C.: Impacts of increasing anthropogenic soluble iron and nitrogen deposition on ocean chemistry, Global Biogeochem. Cy., 23, GB3016, doi:10.1029/2008GB003440, 2009.

Law, C. S., Abraham, E. R., Watson, A. J., and Liddicoat, M.: Vertical diffusion and nutrient supply to the surface mixed layer of the Antarctic Circumpolar Current, J. Geophys. Res., 108, 3272, doi:10.1029/2002JC001604, 2003.

Martin, J. H., Gordon, R. M., and Fitzwater, S. E.: Iron in Antarctic waters. Nature, 345, 156-158, 1990.

Martin, J. H., Fitzwater, S. E., Gordon, R. M., Hunter, C. N., and Tanner, S. J.: Iron, primary production and carbon nitrogen flux studies during the JGOFS North-Atlantic Bloom Experiment, Deep-Sea Res. Pt. I, 40, 115-134, 1993.

Matear, R. and Hirst, A.: Long-term changes in dissolved oxygen concentrations in the ocean caused by protracted global warming, Global Biogeochem. Cy., 17, 12427, doi:10.1029/2002GB001997, 2003.

Mather, R., Reynolds, S., Wolff, G., Williams, R. G., Torres-Valdes, S., Woodward, E. M. S., Landolfi, A., Pan, X., Sanders, R. W., and Achterberg, E.: Phosphorus cycling in the North and South Atlantic Ocean subtropical gyres, Nat. Geosci., 1, 439443, 2008.

Milne, A., Landing, W., Bizimis, M., and Morton, P.: Determination of $\mathrm{Mn}, \mathrm{Fe}, \mathrm{Co}, \mathrm{Ni}, \mathrm{Cu}, \mathrm{Zn}, \mathrm{Cd}$ and $\mathrm{Pb}$ in seawater using high resolution magnetic sector inductively coupled mass spectrometry (HR-ICP-MS), Analyt. Chim. Acta, 665, 200-207, 2010.

Moffett, J. W. and Ho, J.: Oxidation of cobalt and manganese in seawater via a common microbially catalyzed pathway, Geochim. Cosmochim. Acta, 60, 3415-3424, 1996.

Murphy, J. and Riley, J. P.: A modified single solution method for the determination of phosphate in natural waters, Analyt. Chim. Acta, 27, 31-36, 1962.

Noble, A. E., Saito, M. A., Maiti, K., and Benitez-Nelson, C. R.: Cobalt, manganese, and iron near the Hawaiian Islands: A potential concentrating mechanism for cobalt within a cyclonic eddy and implications for the hybrid-type trace metals, Deep-Sea Res. Pt. II, 55, 1473-1490, doi:10.1016/j.dsr2.2008.02.010, 2008.

Noble, A. E., Lamborg, C. H., Ohnemus, D. C., Lam, P. J., Goepfert, T. J., Measures, C. I., Frame, C. H., Casciotti, K. L., DiTullio, G. R., Jennings, J., and Saito, M. A.: Basin scale inputs of cobalt, iron, and manganese from the Benguela-Angola front to the South Atlantic Ocean, Limnol. Oceanogr., 57, 989-1010, 2012.

Oschlies, A., Schulz, K., Riebesell, U., and Schmittner, A.: Simulated 21st century's increase in oceanic suboxia by $\mathrm{CO}_{2}$ enhanced biotic carbon export, Global Biogeochem. Cy., 22, GB4008, doi:10.1029/2007GB003147, 2008.

Peterson, R. G. and Stramma, L.: Upper-level circulation in the South Atlantic Ocean, Prog. Oceanogr., 26, 1-73, doi:10.1016/0079-6611(91)90006-8, 1991.

Pohl, C., Croot, P. L., Hennings, U., Daberkow, T., Budeus, G., and von der Loeff, M. R.: Synoptic transects on the distribution of trace elements $(\mathrm{Hg}, \mathrm{Pb}, \mathrm{Cd}, \mathrm{Cu}, \mathrm{Ni}, \mathrm{Zn}, \mathrm{Co}, \mathrm{Mn}, \mathrm{Fe}$, and $\mathrm{Al})$ in surface waters of the Northern- and Southern East Atlantic, J. Mar. Systems, 84, 28-41, 2011.
Poole, R. and Tomczak, M.: Optimum multiparameter analysis of the water mass structure in the Atlantic Ocean thermocline, Deep Sea Res. Pt. I, 46, 1895-1921, 1999.

Reid, J. L.: On the total geostrophic circulation of the SouthAtlantic Ocean - flow patterns, tracers, and transports, Progr. Oceanogr., 23, 149-244, 1989.

Reid, J. L.: On the total geostrophic circulation of the North Atlantic Ocean: Flow patterns, tracers and transports, Progr. Oceanogr., 33, 1-92, 1994.

Rijkenberg, M. J. A., Steigenberger, S., Powell, C. F., van Haren, H., Patey, M. D., Baker, A. R., and Achterberg, E. P.: Fluxes and distribution of dissolved iron in the eastern (sub-) tropical North Atlantic Ocean, Global Biogeochem. Cy., 26, GB3004, doi:10.1029/2011gb004264, 2012.

Saito, M. A. and Goepfert, T. J.: Zinc-cobalt colimitation of Phaeocystis antarctica, Limnol. Oceanogr., 53, 266-275, 2008.

Saito, M. A. and Moffett, J. W.: Complexation of cobalt by natural organic ligands in the Sargasso Sea as determined by a new highsensitivity electrochemical cobalt speciation method suitable for open ocean work, Mar. Chem., 75, 49-68, 2001.

Saito, M. A. and Moffett, J. W.: Temporal and spatial variability of cobalt in the Atlantic Ocean, Geochim. Cosmoch. Acta, 66, 1943-1953, 2002.

Saito, M. A., Moffett, J. W., and DiTullio, G. R.: Cobalt and nickel in the Peru upwelling region: A major flux of labile cobalt utilized as a micronutrient, Global Biogeochem.1 Cy., 18, GB4030, doi:10.1029/2003GB002216, 2004.

Saito, M. A., Moffett, J. W., Chrisholm, S. W., and Watherbury, J. B.: Cobalt limitation and uptake in Prochlorococcus, Limnol. Oceanogr., 47, 1629-1636, 2002.

Saito, M. A., Goepfert, T. J., Noble, A. E., Bertrand, E. M., Sedwick, P. N., and DiTullio, G. R.: A seasonal study of dissolved cobalt in the Ross Sea, Antarctica: micronutrient behavior, absence of scavenging, and relationships with $\mathrm{Zn}, \mathrm{Cd}$, and P, Biogeosciences, 7, 4059-4082, doi:10.5194/bg-7-4059-2010, 2010.

Shelley, R. U., Zachhuber, B., Sedwick, P. N., Worsfold, P. J., and Lohan, M. C.: Determination of total dissolved cobalt in UV-irradiated seawater using flow injection with chemiluminescence detection, Limnol. Oceanogr., 8, 352-362, doi:10.1029/2009JC005880, 2010.

Shelley, R. U., Sedwick, P. N., Bibby, T. S., Cabedo-Sanz, P., Church, T. M., Johnson, R. J., Macey, A. I., Marsay, C. M., Sholkovitz, E. R., Ussher, S. J., Worsfold, P. J., and Lohan, M. C.: Controls on dissolved cobalt in surface waters of the Sargasso Sea: Comparisons with iron and aluminum, Global Biogeochem. Cy., 26, GB2020, doi:10.1029/2011GB004155, 2012.

Sherrell R. M. and Boyle E. A.: The trace metal composition of suspended particles in the oceanic water column near Bermuda, Earth Planet. Sci. Lett., 111, 155-174, 1992.

Schmitz Jr., W. J.: On the interbasin-scale thermocline circulation, Rev. Geophys., 33, 151-173, 1995.

Strickland, J. D. H. and Parsons, T. R.: A pracitcal handbook of seawater analysis, 1st Edn. , Fisheries Research Board of Canada, Bulletin. No 167, p. 65, 1968.

Tomczak, M. and Godfrey, J. S.: Regional Oceanography: an Introduction, 2nd Edn., Pergamon, Oxford, 422 pp., 2003.

Tovar-Sanchez, A., Sanudo-Wilhelmy, S. A., Kustka, A. B., Agusti, S., Dachs, J., Hutchins, D. A., Capone, D. G., and Duarte, C. M.: Effects of dust deposition and river discharges on trace metal 
composition of Trichodesmium spp. in the tropical and subtropical North Atlantic Ocean, Limnol. Oceanogr., 51, 1755-1761, 2006.

Tovar-Sanchez, A. and Sanudo-Wilhelmy, S. A.: Influence of the Amazon River on dissolved and intra-cellular metal concentrations in Trichodesmium colonies along the western boundary of the sub-tropical North Atlantic Ocean, Biogeosciences, 8, 217225, doi:10.5194/bg-8-217-2011, 2011.

Vega, M. and van den Berg, C. M. G.: Determination of cobalt in seawater by catalytic adsorptive cathodic stripping voltammetry, Anal. Chem., 69, 874-881, 1997.

Webb, D. J. and Suginohara, N.: Oceanography: Vertical mixing in the ocean, Nature, 409, 6816, doi:10.1038/3505117, 2001.
Weiss, R.: The solubility of nitrogen, oxygen, and argon in water and seawater, Deep Sea Re. Oceanogr. Abstr., 17, 721-756, 1970.

Whitworth III, T. and Nowlin Jr, W. D.: Water masses and currents of the Southern Ocean at the Greenwich Meridian, J. Geophys. Res., 92, 6462-6476, 1987.

Wong, G. T. F., Pai, S. C., and Chung, S. W.: Cobalt in the western Philippine Sea, Oceanologica Acta, 18, 631-638, 1995.

You, Y.: Quantitative estimate of Antarctic Intermediate Water contributions from the Drake Passage and the southwest Indian Ocean to the South Atlantic, J. Geophys. Res., 107, 3031, doi:10.1029/2001JC000880, 2002. 